\author{
Universidade de Brasília \\ Instituto de Ciências Exatas \\ Departamento de Ciência da Computação
}

\title{
Interatividade,Construtuvismo e Construcionismo: Bases Sólidas para um Bom Ambiente Virtual - Um Estudo de Caso Sobre o Uso do Moodle
}

\author{
Rodrigo Vaz dos Santos \\ Monografia apresentada como requisito parcial \\ para conclusão do Curso de Computação - Licenciatura \\ Orientador \\ Prof. Dr. Marco Carvalho
}

Brasília

2007 
Universidade de Brasília - UnB

Instituto de Ciências Exatas

Departamento de Ciência da Computação

Curso de Computação - Licenciatura

Coordenador: Prof. Dr. Marco Carvalho

Banca examinadora composta por:

Prof. Dr. Marco Carvalho (Orientador) - Universidade de Brasjlia

\section{CIP - Catalogação Internacional na Publicação}

Rodrigo Vaz dos Santos.

Interatividade,Construtuvismo e Construcionismo: Bases Sólidas para um Bom Ambiente Virtual - Um Estudo de Caso Sobre o Uso do Moodle/ Rodrigo Vaz dos Santos. Brasília : UnB, 2007.

47 p. : il. ; $29,5 \mathrm{~cm}$.

Monografia (Graduação) - Universidade de Brasília, Brasília, 2007.

1. Ensino a Distância, 2. Interatividade, 3. Construtivismo, 4. Construcionismo, 5. Ambientes Virtuais

CDU 004

Endereço: Universidade de Brasília

Campus Universitário Darcy Ribeiro - Asa Norte

CEP 70910-900

Brasília - DF - Brasil 


\author{
Universidade de Brasília \\ Instituto de Ciências Exatas \\ Departamento de Ciência da Computação
}

\title{
Interatividade,Construtuvismo e Construcionismo: Bases Sólidas para um Bom Ambiente Virtual - Um Estudo de Caso Sobre o Uso do Moodle
}

\author{
Rodrigo Vaz dos Santos \\ Monografia apresentada como requisito parcial \\ para conclusão do Curso de Computação - Licenciatura
}

Prof. Dr. Marco Carvalho (Orientador)

Universidade de Brasjlia

Prof. Dr. Marco Carvalho

Coordenador do Curso de Computação - Licenciatura

Brasília, 6 de Dezembro de 2007 


\section{Dedicatória}

Dedico este trabalho:

Primeiramente a Deus que operou seus milagres ao abrir as portas desta Universidade para que eu, aqui, fosse mais que vencedor e manifestasse sua Glória e que me supriu com força, entendimento e sabedoria;

aos meus pais, Miguel Rodrigues e Maria Aparecida, que sempre incentivaram a continuar e nunca desistir, que foram minha base sólida de amor e caráter;

aos meus irmãos Rafael Vaz e Eduardo Vaz que são exemplos de inteligência e superação e a nossa irmãzinha do coração, Glenda, que foi colocada em nossas vidas para trazer alegria e felicidade;

aos meus pastores, Adroaldo Veloso, Elias Junior e Marcelo Freitas, por serem guias ao falarem a Palavra de Deus, Palavra essa por sobre a qual tenho caminhado;

à Milena de Sousa Soares, minha noiva, que muitas vezes se mostrou mais forte que eu ao me apoiar para que eu fosse o melhor e que junto comigo persistiu no sonho de me formar na Universidade;

à UNB e seu corpo docente pelo conhecimento adquirido

e a todos os amigos e companheiros que estiveram comigo durante todo estes anos de Universidade.

Rodrigo Vaz dos Santos. 


\section{Resumo}

Este trabalho estuda o uso e o aproveitamento da Plataforma Moodle, oferecida no Ambiente do CEAD, quanto a duas de suas bases filosóficas, o Construtivismo e o Construcionismo, fazendo uma análise quanto ao nível de interação que os professores de Introdução a Micro Informática - IMI estão oferecendo no ambiente. Para isso foi usado um questionário como instrumento de coleta de dados junto aos alunos para levantar a atual situação da disciplina e possiveis falhas, indicando soluções para resolver problemas quanto a interatividade dos alunos no Ambiente Virtual e com o Ambiente Virtual.

Palavras-chave: Ensino a Distância, Interatividade, Construtivismo, Construcionismo,Ambientes Virtuais 


\section{Abstract}

This work studies the use and the exploitation of the Moodle Platform at CEAD/UnB, in hespect of both of its philosophical bases, the Construtivism and the Construcionism, analysing the interaction level betwem lectuners and students of Introduction to Micro-Informatics-IMI. A questionnaire was used along with a instrument of collection data to the pupils to raise the current situation of disciplines and possibles imperfections, indicating solutions to solve problems on the interaction of the pupils with the Virtual Environment.

Keywords: Distance Education, Interativicty, Construtivism, Construcionism Virtual Environment 


\section{Conteúdo}

$\begin{array}{lr}\text { Lista de Figuras } & 9\end{array}$

$\begin{array}{ll}\text { Lista de Tabelas } & 10\end{array}$

$\begin{array}{lll}\text { Capítulo } 1 \text { Introdução } & 11\end{array}$

$\begin{array}{lll}\text { Capítulo } 2 & \text { Revisão Teórica } & 13\end{array}$

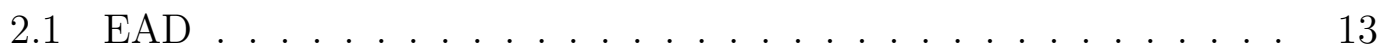

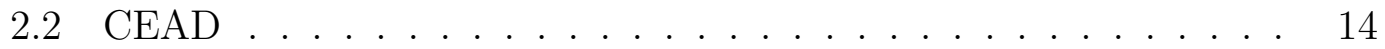

2.3 Interação . . . . . . . . . . . . . . . . . . . . 15

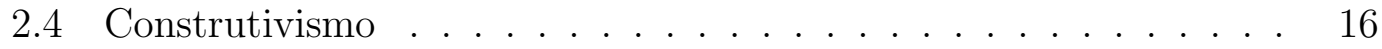

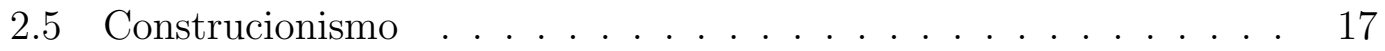

2.6 Moodle. . . . . . . . . . . . . . . . . . . . 18

2.6 .1 Histórico . . . . . . . . . . . . . . . . . . . . . . 19

$2.6 .2 \quad \mathrm{O}$ ambiente . . . . . . . . . . . . . . . . 19

2.6.3 Filosofia do Moodle . . . . . . . . . . . . . . . . . 28

$\begin{array}{lll}\text { Capítulo } 3 \text { A Pesquisa } & 31\end{array}$

3.1 Instrumento . . . . . . . . . . . . . . . . . . . . 31

3.1 .1 Analise Exploratória e Qualitativa . . . . . . . . . . . 31

3.1.2 Delimitação do Estudo para Coleta de Dados . . . . . . . 32

3.1 .3 Analise Sistemática dos Dados . . . . . . . . . . . . . 33 


\section{Lista de Figuras}

2.1 Pesquisa Moodle. Fonte: http://www.e-learning-mt.com. . . . . . 18

2.2 Tela Inicial. . . . . . . . . . . . . . . . . . . . . . . . . . 20

2.3 Início da Edição. . . . . . . . . . . . . . . . . . . . . . . . . . . . 21

2.4 Menu das Atividades. . . . . . . . . . . . . . . . . . . . . 22

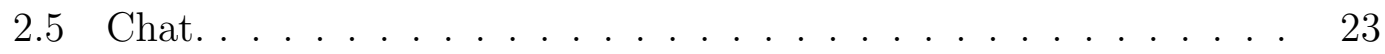

2.6 Fórum. . . . . . . . . . . . . . . . . . . . 23

2.7 Materiais. . . . . . . . . . . . . . . . . 24

2.8 Tarefa. . . . . . . . . . . . . . . . . 25

2.9 Questionario. . . . . . . . . . . . . 26

2.10 Wiki. .......................... 27

2.11 Menu de Administração. . . . . . . . . . . . . . . . . . . . . 28

3.1 Gráfico Idade. . . . . . . . . . . . . . . . . . . . . . 33

3.2 Participação dos Colegas . . . . . . . . . . . . . . . . . . . . . 35

3.3 Avaliação das Ferramentas Comunicativas. . . . . . . . . . . . . . 36

3.4 Gráfico Modalidade Preferida . . . . . . . . . . . . . . . . . . . 38 


\section{Lista de Tabelas}

3.1 Tabela Quantidade de Disciplinas feitas no Moodle . . . . . . . 33

3.2 Tabela Acesso Semanal . . . . . . . . . . . . . . . . . . . . . . . 34

3.3 Tabela Aumento do Acesso Durante o Semestre . . . . . . . . . . 34

3.4 Tabela Participaço na Construção da Disciplina . . . . . . . . . . 34

3.5 Opiniões em Listas . . . . . . . . . . . . . . . . . . . . . 35

3.6 Ferramenta Que Mais Gostou . . . . . . . . . . . . . . . 36

3.7 Escala das Ferramentas mais Usadas . . . . . . . . . . . . . . . 36

3.8 Escala das Ferramentas que Mais Contribuiram Para o Prendizado 37

3.9 Incentivo do Professor . . . . . . . . . . . . . . . . . . 37 


\section{Capítulo 1}

\section{Introdução}

Em um cenário que com grande pressa se monta a cada dia, onde o tempo, que tem o papel principal e dita a velocidade com a qual os outros atores se relacionam com ele e entre si, acha-se um mundo em que a pressa, o dinamismo e a facilidade se tornam cada vez mais comuns e cada vez mais caros. A tecnologia, como ponto de dinamismo e facilidade, apressa as relações, encurta as distâncias, dinamiza acordos e tratados dando ao homem um poder sobre esse grande ator que rege aceleradamente o universo, o tempo.

Nesse contexto de que o tempo é algo muito caro, avalia-se a necessidade de novas ferramentas que facilitem o acesso e que diminuam as distâncias para romper barreiras que impedem que o ensino chegue ao seu destino.

A inclusão de plataformas de ensino à distância nas universidades oferece um vasto campo de estudo e é preciso avaliar essa nova estrutura possibilitando um melhoramento da sua aplicação, para assim propiciar, não só um crescimento numérico, mas também uma base solida e firme para este crescimento podendo assim, com segurança e tranqüilidade, aplicar também a educação a distância em outros níveis de estudo.

O objetivo desta pesquisa consiste em analisar o uso da Plataforma Moodle no Ambiente do CEAD - Centro de Educação a Distância da Universidade de Brasília, referente a duas de suas bases filosóficas: Construtivismo e Construcionismo. Para a análise do ambiente se tomou por base um conjunto de dados reunidos através de uma pesquisa feita com quarenta alunos das turmas de Introdução a Micro Informática - IMI. A base de dados foi criada através de um questionário, passado aos alunos, cuja intenção foi mostrar como a plataforma é usada em relação ao objetivo inicial de sua criação que é ser uma Sala de Aula Virtual.

Portanto, esse estudo pretende fazer um diagnóstico do Uso do Moodle referente a níveis de Interatividade, quanto às bases construtivista e construcionista da Plataforma Moodle. 
Para a realização deste trabalho há razões pessoais e acadêmicas. Pessoais, pois o autor já utilizou a plataforma em questão, como estudante e como professor, e durante esse período houve um interesse por um estudo mais profundo do Moodle por ter sido uma experiência agradável, já que outras experiências com Ambientes Virtuais não havia logrado êxito. Dessa experiência surgiram algumas dúvida:

\section{De quem é a culpa se um aluno desiste de um curso?}

ou ainda:

\section{Por que muitos cursos não duram durante muito tempo?}

Para os problemas propostos, a metodologia usada foi um estudo de caso dividido em quatro fases:

1 - Análise dos elementos teóricos que formaram a base da pesquisa;

2 - Formulação do Questionário objetivando extrair dados referentes ao objeto de estudo;

3 - Análise dos dados obtidos através do Questionário; e

4 - Resultados dos dados e sugestões quanto ao Uso da Plataforma Moodle pela disciplina. 


\section{Capítulo 2}

\section{Revisão Teórica}

\section{$2.1 \quad \mathrm{EAD}$}

A Educação a Distância (EAD) tem se mostrado através do tempo uma ferramenta valiosa para o Sistema Educacional. Hoje ao ver sua rápida evolução em relação à educação tradicional não se imagina sua origem. Segundo (LANDIN [1997]) algumas fontes históricas apontam seu surgimento em 1833, na Suécia, seu sistema, nesta época era baseado em correspondência, mas temos exemplos mais antigos como as cartas de Paulo às igrejas do novo testamento (DORNELLES [2001]) bíblia, cartas estas que traziam ensinamentos quanto ao modo das igrejas se conduzirem.

A forma de se comunicar à distância mais eficaz desde os tempos antigo até cerca de dois séculos atrás era por meio de correspondência e, conforme cita Landin (LANDIN [1997]) a EAD começa também por correspondência e a cada vez que a forma de se comunicar evolui, também evolui a EAD criando a partir de cada nova forma de se comunicar uma nova opção para a educação a Distância. Exemplo disso foi a criação, em 1969, da "Open Unversity" (UNIVERSITY [2007]), na Inglaterra, que funciona até hoje. Uma das razões de sucesso desta universidade a distância foi o uso dos vários meios de comunicação da época, desde material impresso até rádio, televisão e vários centros de atendimento espalhados no território Inglês conforme relatam (HOLMBERG [1981]), (NUNES [1992]), (ALVES [1994]), (PRETI [1996]),(MOORE and KEARSLEY [1996]) e (LANDIN $[1997])$.

O grande desenvolvimento dos meios de comunicação levou a EaD a se popularizar. Hoje para se escolher um meio de comunicação eficiente para EaD, é preciso que o mesmo desperte a atenção e motive os alunos, que apresente todo o conteúdo a ser assimilado, seja orientado e estruturado adequadamente, assegure a realimentação, promova a transferência e facilite a retenção de conhecimento. A constatação desses fatores não deve omitir as limitações que possam impedir a eficácia da EAD. (MARTINS [1991]) 
Mesmo que a EAD se apresente como uma metodologia não-convencional, ainda assim é preciso um planejamento cauteloso do processo de transmissão e de construção do conhecimento. (MASON and KAYE [1989])

Com os avanços da tecnologia a EAD ganhou o mundo inclusive o Brasil. O ensino via rádio em 1923 foi o primeiro meio de ensino à distância em massa no Brasil. Nesta época é criada a Rádio Sociedade do Rio de Janeiro, fundada por Roquete Pinto, que foi doada para o Ministério da Educação, daí ela passa a se chamar Rádio-MEC.Já nos anos 60 aparece as emissoras de TV que incrementam a EAD e nos anos 70 já eram apresentados os telecursos evoluindo até os dias de hoje onde temos em computadores e internet os principais meios para a Educação a Distância.

\subsection{CEAD}

A UnB foi pioneira em experiências com estudos à distância com universitários no Brasil e em 1979 ofereceu cinco ursos de extensão. (NUNES [1992]) relata o seguinte: "A iniciativa inovadora da UnB não logrou sucesso, principalmente dado a inadequação do discurso de sua direção, que apresentava a educação a distância como substituto da educação presencial e um meio de resolver os conflitos políticos existentes na época. Ademais, a falta de competência na gestão do projeto, levou a UnB a estabelecer um programa de educação a distância que acabava por excluir a possibilidade de colaboração crítica dos quadros da própria Universidade na produção avaliação do saber e pluralismo de idéia".

Em 1985, segundo Nunes (NUNES [1992]) é retomado o Programa de EAD da Unb, transformando-se no Centro de Educação Aberta Continuada (CEAD). Desta vez foram oferecidos dez cursos inclusive uma primeira experiência com software. Daí surge então a UnbVirtual, subordinada ao CEAD, oferecendo em sua grade disciplinas de graduação. Esta evolução continua até os dias de hoje saindo do uso da UnbVirtual e atualmente usando a plataforma Moodle.

Conforme o Decreto 2.494, de 10.02.1998, da Legislação Brasileira sobre educação a distância, "Educação a Distância é uma nova forma de ensino que possibilita a auto-aprendizagem, com a mediação de recursos didáticos sistematicamente organizados, apresentados em diferentes suportes de informação, utilizados isoladamente ou combinados, e veiculados pelos diversos meios de comunicação".

Nesta definição pode-se observar quase todas as características mais marcantes da educação a distância relacionadas por (LANDIN [1997]) no estudo comparativo que fez de conceitos apresentados por estudiosos famosos, como Garcia Aretio(ARETIO [1994]), Moore e Kearley (MOORE and KEARSLEY [1996]), Holmberg(HOLMBERG [1981]), Dohmem(DOHMEN [1967]) e outros. São as seguintes características: Separação professor/aluno, meios técnicos, organização (apoio-tutoria), aprendizagem independente, Comunicação bidirecional, enfoque 
tecnológico, comunicação massiva e procedimentos industriais.

O teórico G Dohmen (DOHMEN [1967]) (apud LANDIN [1997]) afirma:

"Educação a Distância é uma forma sistematicamente organizada de autoestudo, onde o aluno se instrui a partir do material que lhe é apresentado, onde o acompanhamento e a supervisão do sucesso do aluno são levados a cabo por um grupo de professores. Isto é possível à distância através da aplicação de meios de comunicação capazes de vencer essa distância mesmo sendo longa. O oposto de educação a distância é a educação direta ou educação face a face: um tipo de educação que tem lugar com o contato direto entre professores e alunos".

O desenvolvimento das tecnologias da informação e da comunicação fez com que MOORE [1972] (apud LANDIN [1997]) á começasse a falar dos meios eletrônicos, a comunicação entre professor e aluno mediada por meios eletrônicos:

"O ensino a distância é o tipo de método de instrução em que as condutas docentes acontecem a parte das discentes, de tal maneira que a comunicação entre o professor e o aluno se possa realizar mediante textos impressos, por meios eletrônicos, mecânicos ou por outras técnicas".

Ao se olhar algumas linhas referentes a descrição de EAD nota-se que a educação a distância se baseia em princípios construtivista e cooperativos facilitadas pelas tecnologias de interação imediata, que partem do principio que o aluno construa seu conhecimento e neste processo o aluno é a peça fundamental na construção do conhecimento.

\subsection{Interação}

Ao se falar de EAD a primeira idéia que nasce é a que o aluno estudará por conta própria pois, a princípio, não haveria interação com os professores e com outros alunos, e se isso fosse verdade, haveriam grandes problemas pois, segundo a sociologia(VIEIRA [2002]), o homem não se identifica com objetos, mas sim com outro ser humano, existe uma necessidade de interação, o homem é um ser social, ele precisa interagir com outros seres humanos e ainda precisa pertencer a algo, essas duas questões dão um nível de segurança a uma pessoas. Para provar essas necessidades basta olhar para a história de cada indivíduo, em regra o homem quando nasce está inserido em uma família e fica nela por um bom tempo. Em um primeiro estágio apenas se relacionam com os pais, tem-se o segundo estágio onde entra o grupo social e daí ele começa a interagir com esse grupo e depois, em um terceiro estágio vem a escola. 
Desde o nascimento as pessoas se relacionam e esse relacionamento, em uma primeira instância, é uma questão de sobrevivência pois um bebê não consegue se alimentar sozinho, daí nasce a relação de dependência e essa relação que começa com os pais vai ganhando novos atores na medida que a criança vai sendo inserida nos grupos sociais e na escola. Assim essa dependência é imposta ao indivíduo continuamente ao longo da vida através do processo de adaptação pelo qual, segundo (DEMO [1995]), uma criança assume o comportamento desejado pelos adultos, a necessidade de ser membro da comunidade sendo essa necessidade incorporada à sua personalidade.

Se uma pessoa não se sentir inserida caracteriza-se um problema, Pedro Demo (DEMO [1995]) diz o seguinte:

"O sistema social é composto da interação dos indivíduos que aparecem tanto como atores, quanto como objetos para orientar outros."

Por isso a EAD tem que oferecer uma boa estratégia de interação pois isto é fundamental e é uma necessidade humana. Cursos a distância que não oferecem um bom programa de interação terão dificuldades de manter seus alunos devido os mesmos não se sentirem participantes de um grupo.

"A gente não estuda só em certos momentos, em certas horas ou em certos espaços, mas estuda toda hora, durante a vida toda, com toda parafernália disponível, sobre tudo a eletrônica" (DEMO [data])

A evolução da EAD está diretamente ligada à evolução da comunicação. Através das redes de computadores a EAD ganha possibilidades incríveis na área de interação, isso por causa da internet que possibilita uma resposta imediata, agora é possível ter respostas rápidas e instantâneas, contudo, para o sucesso de um Ambiente Virtual de EAD, não basta esse ambiente apenas propiciar a interação entre as partes tem ainda que, de alguma forma, induzir essa interação, sendo que essa interação não pode ser apenas na escolha de opções através do navegador, mas deve trazer o objeto de estudo à realidade do aluno sempre com o intuito de estimular e desafiar permitindo assim o desenvolvimento do aluno. Mas essa interação não deve agir só entre o aluno e computador, também tem que ser direcionado entre aluno e aluno e aluno e professor podendo ser ou não através do computador.

\subsection{Construtivismo}

"Todo saber é conseqüência de uma experiência ou de fatores humanos inatos e, dada esta condição, não poderíamos nunca confrontar o saber obtido com o mundo objetivo existente antes que ele fosse imaginado e transformado pela experiência humana e as propriedades inatas do espírito humano, agente do conhecimento." (MORETTO [2003]) 
"O construtivismo parte do observador que constrói ou inventa a realidade com a qual ele estabelece uma corrente dialética por intermédio da experiência."(MORETTO [2003])

' '(..) O papel do professor deixará de ser o de entregador da informação para ser o facilitador, supervisor, consultor do aluno no processo de resolver o seu problema.' ' (VALENTE [1999]).

Segundo Piaget (PIAGET [1975]) o ato de aprender é o mesmo que agir, por isso é atribuído ao educador a tarefa de colocar os alunos diante de situações variadas para que eles próprios busquem soluções para assim construírem seu conhecimento. O construtivismo traz como pressuposto que os indivíduos reagem ao mundo não como ele é objetivamente, mas sim como ele é percebido, qualquer pessoa ao se referir a uma situação a qual participa inclui a si mesmo na observação que faz, ou seja, o saber é construído de acordo com as relações ou interações que o aluno tem com o objeto de estudo seja ele qual for.

"O uso do computador só funciona efetivamente no processo de ensino e aprendizagem se for inserido num contexto de atividade que desafiem o grupo em seu crescimento. Espera-se que o aluno construa o conhecimento na relação consigo próprio, com os outros (professores e colegas) e com a máquina.' '(WEISS and da CRUZ [1999])

No ambiente construtivista o professor é visto de uma forma diferente dos ambientes tradicionais, ele passa a não ser mais o grande e único detentor do saber, agora, segundo Paulo Freire, ele passa a ser "educador-educando". A partir disso o professor se conscientizando da sua nova posição(postura), a de um facilitador, começa a entender que todos os processos de aprendizagem tem que passar por uma interação entre o sujeito da aprendizagem e o objeto, podendo ser o objeto tanto o próprio professor, o computador, os outros alunos ou ainda o assunto e neste novo contexto é o sujeito que conta pois suas relações com o objeto é que vão construindo o seu conhecimento através das interpretações que esse indivíduo faz dessas iterações.

\subsection{Construcionismo}

(...) o construcionismo é uma síntese da teoria da psicologia de Piaget e das oportunidades oferecidas pela tecnologia... em atividades nas quais os estudantes trabalham em direção à construção de um todo compreensível de conhecimentos e fatos contextualizados(...) O fator central do construcionismo é que ele vai além do que é chamado de cognitivo(...) HAREL [1991] (apud PRADO [data]) 
Segundo Gergen (GERGEN [1985]) (apud ELKAIM [1998]), tanto o construtivismo quanto o Construcionismo, partem do pressuposto de que o saber é uma construção do espírito e que o conhecimento não é um reflexo fiel de uma realidade, ou seja, existe uma interdependência entre o observador e o universo observado, eles começam a divergir quanto a construção do saber, enquanto o construtivismo é individualista pois trata a construção do conhecimento como uma relação do individuo com o objeto observado, o Construcionismo considera que a construção do conhecimento é mais efetivo quando o indivíduo constrói algo para outros indivíduos, ou seja, o aprendizado é obtido coletivamente, ou ainda, através de um intercâmbio de conhecimento onde o processo de aprender resulta de uma ação cooperativa entre pessoas interagindo. O Construcionismo, na verdade, é uma ampliação da idéia de construtivismo pois leva em conta as relações sociais e o intercâmbio social e Grandesso (GRANDESSO [2001]) diz o seguinte:

"Se é indivíduo é social, e o social surge na medida que seus componentes são indivíduos."

Ou seja, a interação que há entre indivíduos, desde a postulação de uma frase ou até mesmo a criação de softwares, são produções individuais que constrói o conhecimento dos indivíduos que tem contato com essas produções.

\subsection{Moodle}

O Moodle hoje é um dos ambientes de aprendizagem mais utilizado na educação a distância. A figura 2.1, Pesquisa Moodle, mostra o resultado de uma pesquisa de opinião, feita a alguns anos, onde consta alguns ambientes virtuais e expõe a preferência do internauta.

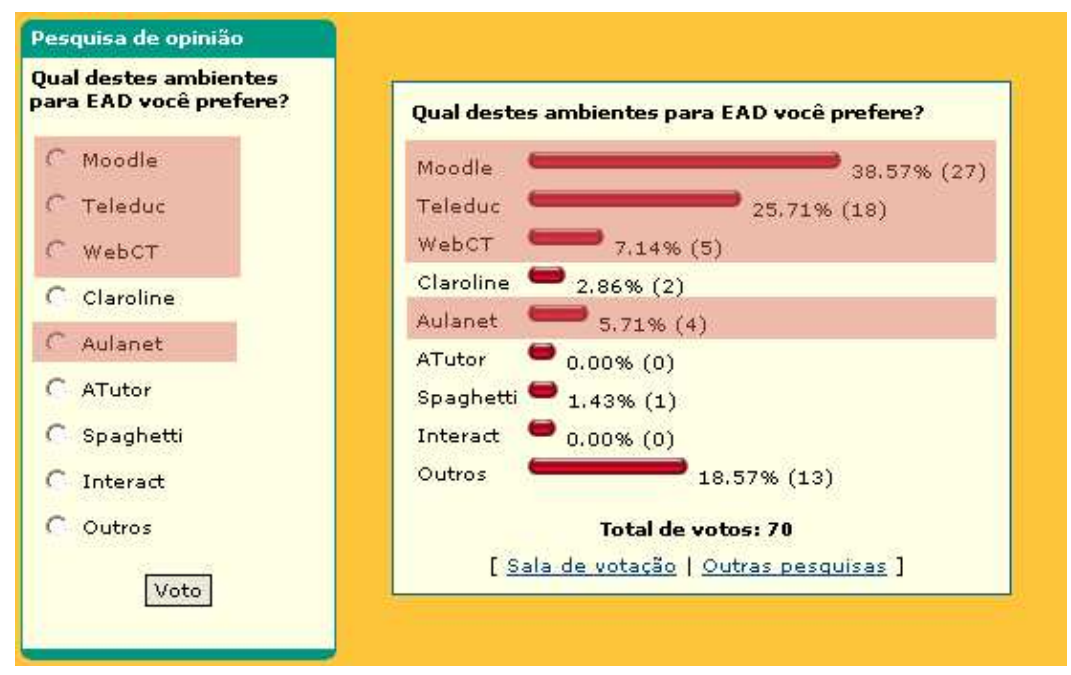

Figura 2.1: Pesquisa Moodle. Fonte: http://www.e-learning-mt.com. 


\subsubsection{Histórico}

Moodle (Modular Object Oriented Distance LEarning) é um sistema para gerenciamento de cursos (SGC) - um programa para computador destinado a auxiliar educadores a criar cursos on-line de qualidade. Tais sistemas de educação via Internet são algumas vezes também chamados de Sistemas de Gerenciamento de Aprendizagem (SGA) ou Ambientes Virtuais de Aprendizagem (AVA). (RANGEL [2004])

O sistema Moodle começou a ser idealizado, no início da década de 90, quando Martin Dougiamas era o Webmaster na Curtin University of Technology na Austrália e responsável pela administração do Ambiente de Aprendizado Virtual, usado pela Universidade naquela época. Martin conhecia muitas pessoas, em escolas e instituições, pequenas e grandes, que gostariam de fazer melhor uso da Internet, mas não sabiam como iniciar devido à grande quantidade de ferramentas tecnológicas e pedagógicas existentes na época. Ele gostaria de proporcionar a essas pessoas uma alternativa gratuita e livre, que pudesse introduzi-los ao universo on-line.(RANGEL [2004])

As crenças de Martin nas inúmeras possibilidades da Educação baseada na Internet o levaram a fazer mestrado e doutorado na área de Educação, combinando sua experiência em ciência da computação com teorias sobre construção do conhecimento e natureza da aprendizagem e da colaboração.

Várias versões do software foram produzidas e descartadas até a versão 1.0 ser aceita e bastante utilizada em 2002. Essa primeira versão era enxuta e foi usada para a realização de estudos de caso que analisavam a natureza da colaboração e da reflexão de pequenos grupos de estudo formados por adultos.

Moodle não é usado apenas por Universidades, mas em escolas de ensino médio, escolas primárias, organizações, companhias privadas e por professores independentes.

\subsubsection{O ambiente}

Uma das principais vantagens do Moodle sobre outras plataformas é um forte embasamento na Pedagogia Construcionista de Seymour Papert (PAPERT [1994]), um psicólogo que foi trabalhar no Laboratório de Inteligência Artificial do MIT, adaptou os princípios do Construtivismo Cognitivo de Piaget e construiu um conjunto de premissas a serem usadas quando aplicando a tecnologia de computadores como auxiliar ao processo de construção de conhecimento. (RANGEL [2004])

Segundo Papert é na universalidade de aplicações do computador e na sua capacidade de simular modelos mecânicos que podem ser programados por crianças, que reside a potencialidade do computador em aprimorar o processo de evolução cognitiva da criança. 


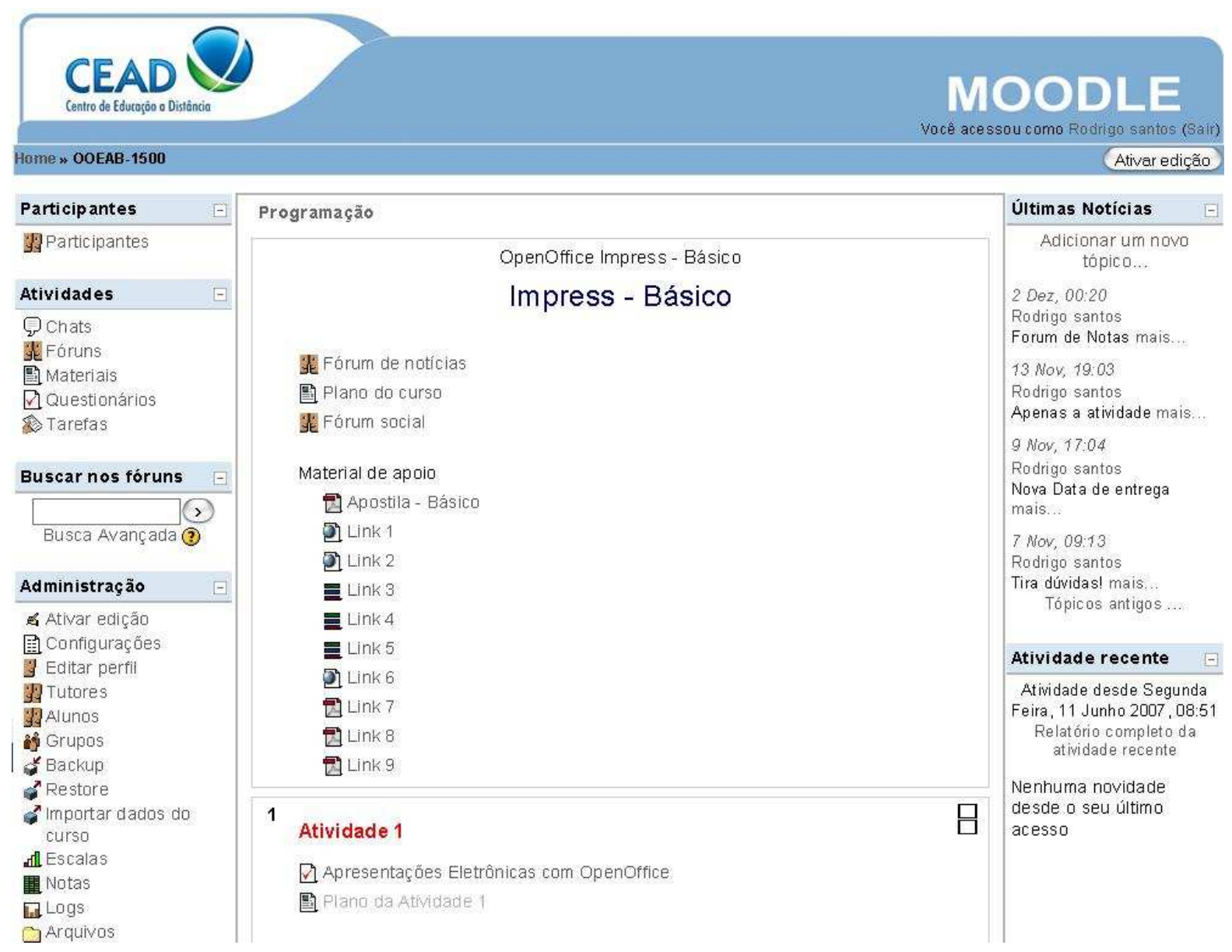

Figura 2.2: Tela Inicial.

A figura acima, figura 2.2, mostra a tela inicial de um curso de Impress acessado pelo professor do curso, nela estão as opções que o professor tem para administrar o curso no ambiente. Moodle é um software de fonte aberta (Open Source Software), o que significa que se pode instalar, usar, modificar e mesmo distribuir o programa (nos termos da GNU General Public Licence). O Moodle pode ser usado, sem modificações, em Unix, Linux, Windows, Mac OS e outros sistemas que suportem PHP. E atualmente está disponível em mais de 40 idiomas. 


\subsubsection{Configurando Atividades}

Construir um curso consiste em acrescentar módulos de atividades na página principal, para que os alunos possam utilizá-los. Pode-se mudar a ordem destes módulos a qualquer momento.

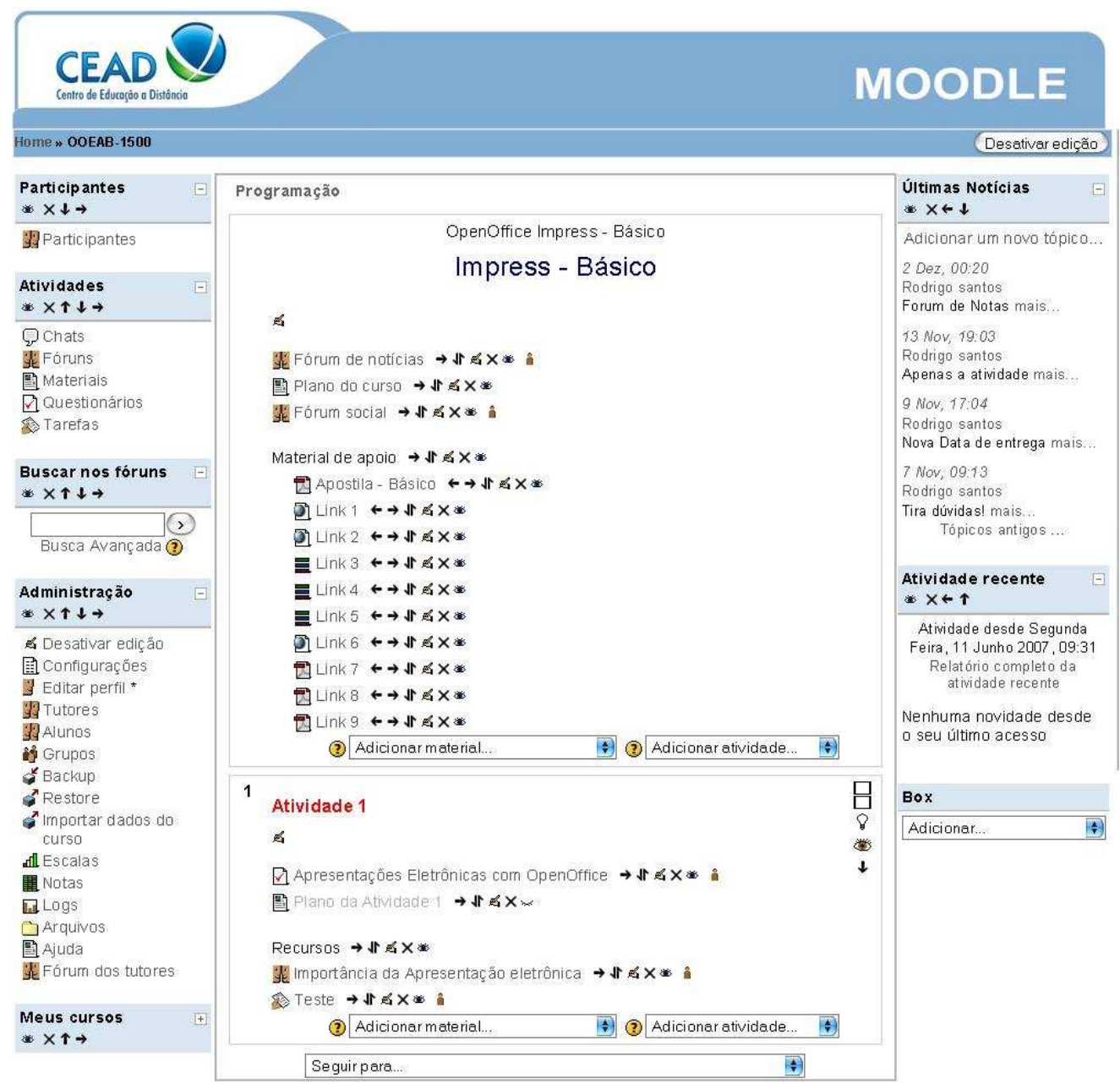

Figura 2.3: Início da Edição.

Para entrar no modo de edição, clique em Ativar Edição em Administração ou no canto superior direito. Este botão mostra ou esconde os controles adicionais que permitem que você manipule a página principal de seu curso. Observe a figura 2.3, figura acima, que os controles de edição estão ativados. 
๔ - o ícone de edição permite que você edite o que estiver perto dele.

(3)- o ícone de ajuda abre uma janelinha de ajuda

* o ícone olho-aberto indica um item que está visíviel mas clicando nele $o$ item ficará oculto para os alunos

w - o ícone olho-fechado fará com que um item escondido fique visível

I - o ícone dupla seta fará com que abra opções de mover os exercícios de uma atividade pra cima ou pra baixo, em qualquer lugar da página principal.

No Moodle existem alguns menus para facilitar a uso do ambiente esses menus são links que levam direto a área do Ambiente que o usuário deseja ir.

\subsubsection{Menu Atividades}

Exibe uma lista de todos os tipos de Atividades Disponíveis na para o curso.

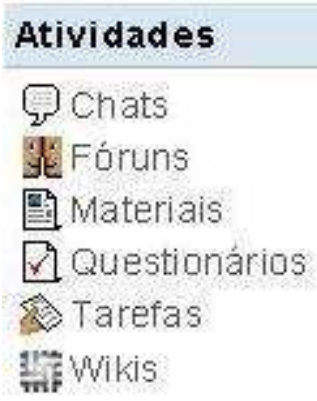

Figura 2.4: Menu das Atividades. 


\subsubsection{Chat}

O Chat é uma oferta de Interação importantíssima para que alunos conversem e tirem dúvidas com seus professores e com os próprios alunos em tempo real, ele pode ser usado em substituição de aulas presenciais podendo as aulas serem on-line através dos Chats.

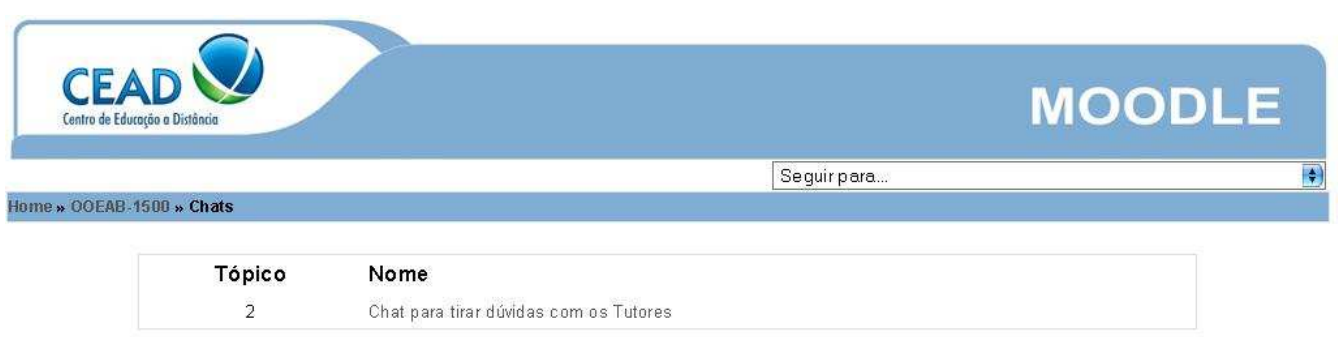

Figura 2.5: Chat.

\subsubsection{Fórum}

Este módulo é de longe o mais importante, é aqui que a discussão acontece. Quanto um novo fórum é acrescentado poderá ser escolhido diversos tipos de fóruns: uma discussão de um único tópico, um fórum geral para todos, ou uma trilha de discussão por tema e por usuário.

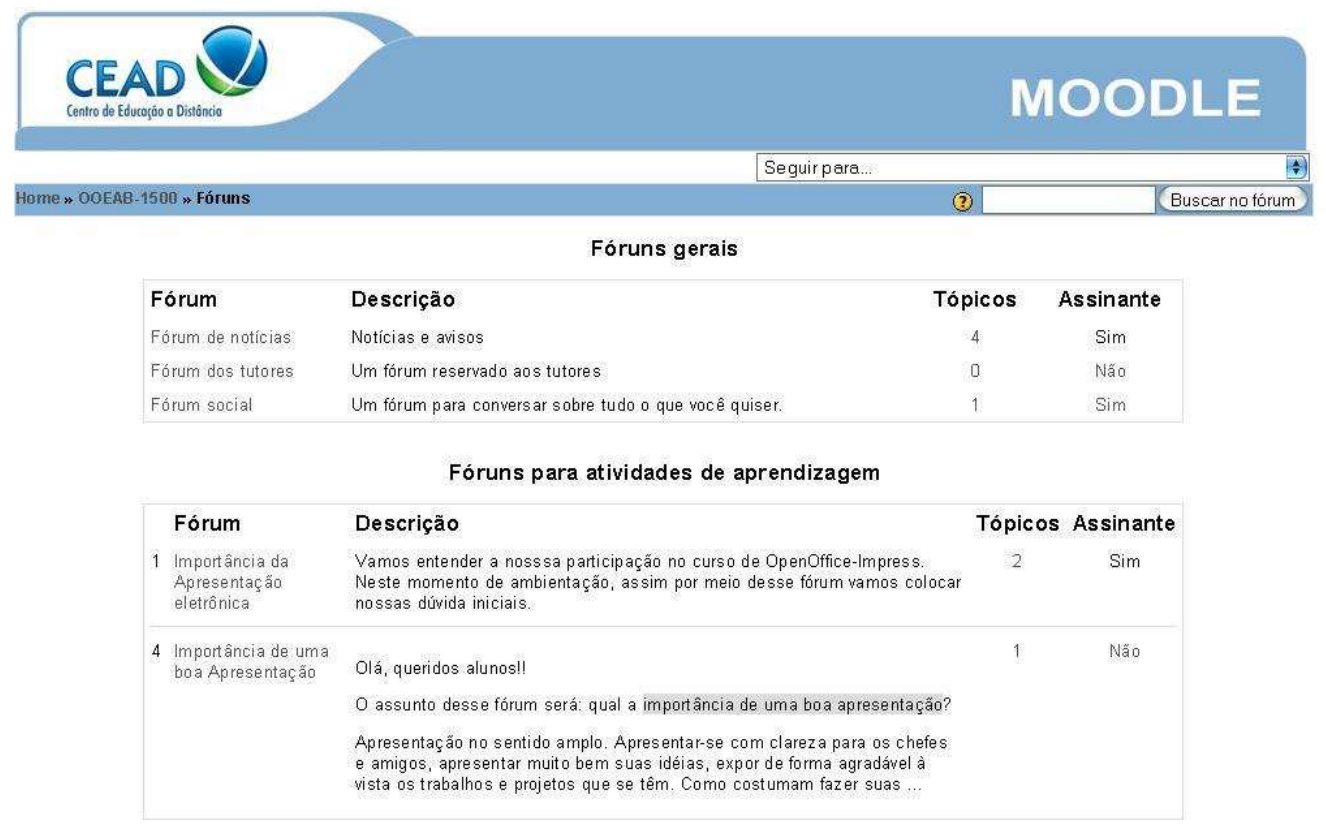

Figura 2.6: Fórum. 


\subsubsection{Materiais}

Materiais é o conteúdo de seu curso. Cada material pode ser um arquivo que o professor tenha carregado, ou pode apontar para uma URL. Também poderá ser criado uma página simples de texto, escrevendo diretamente no formulário.

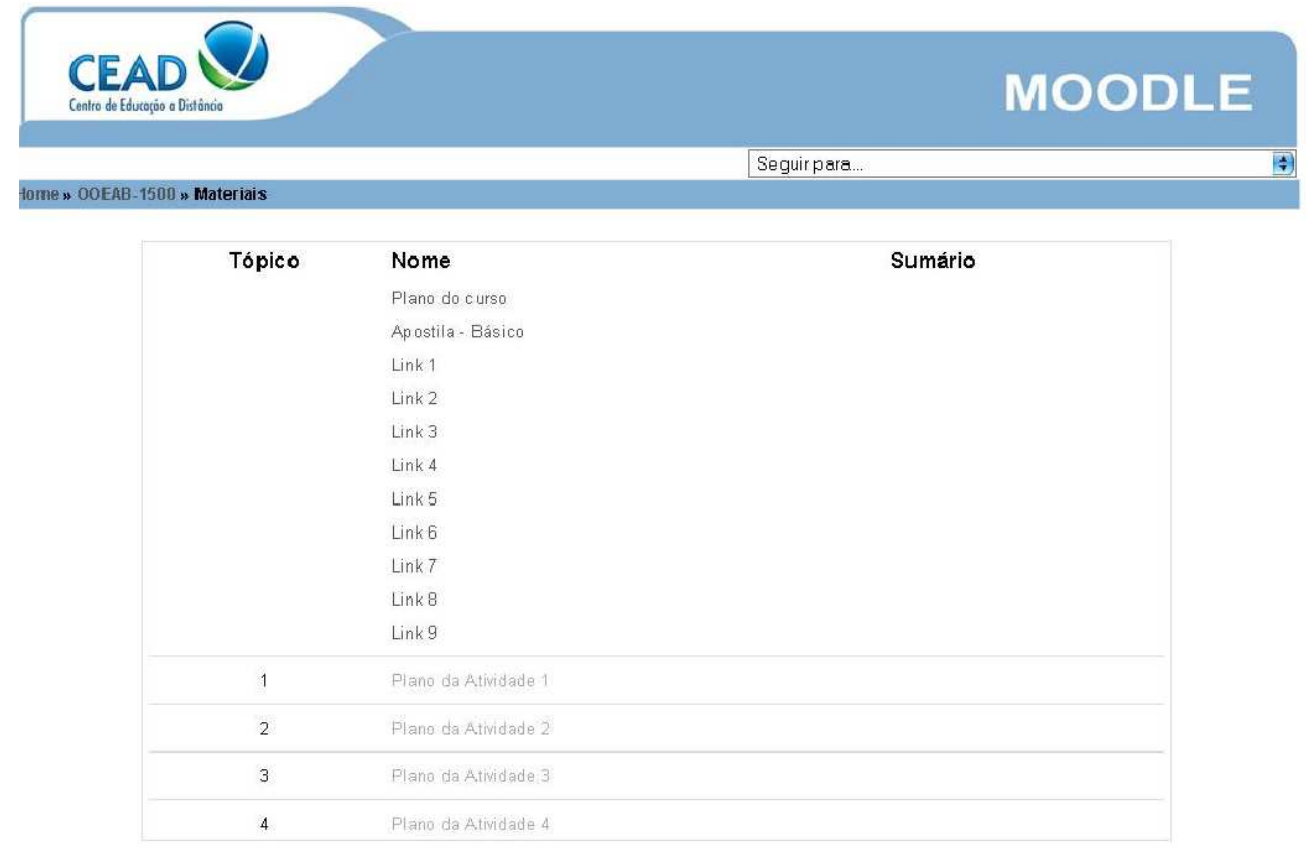

Figura 2.7: Materiais. 


\subsubsection{Tarefa}

Uma tarefa tem uma data limite de entrega e uma nota máxima possível. Os alunos poderão carregar um arquivo no servidor para cumprir a tarefa. A data em que carregam o arquivo é registrada. O professor terá uma página onde poderá ver todos os arquivos, as datas de entrega, e poderão atribuir uma nota e um comentário. Meia hora depois de ser dada a nota a um aluno, o Moodle automaticamente o notificará mediante o envio de uma mensagem.

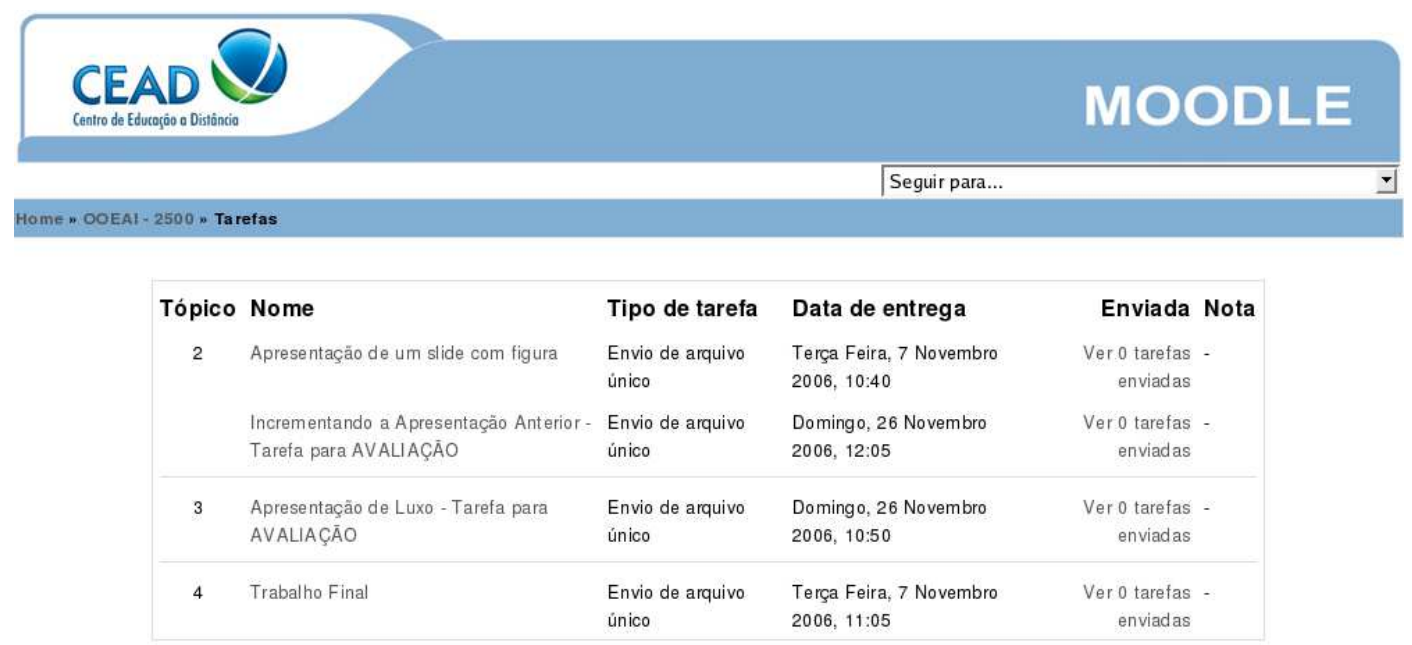

Figura 2.8: Tarefa. 


\subsubsection{Questionário}

Este módulo permite que questioários de teste sejam desenhados e configurados e que podem ser de múltipla escolha, verdadeiro-falso, perguntas de respostas breves, etc. As perguntas são guardadas num banco de dados categorizado e podem ser re-utilizadas dentro dos cursos e mesmo entre cursos. Os questionários podem permitir várias tentativas de resolução. Cada tentativa é automaticamente registrada e cada professor pode escolher se quer oferecer uma explicação ou mostrar a resposta correta. Este módulo inclui a atribuição de notas.

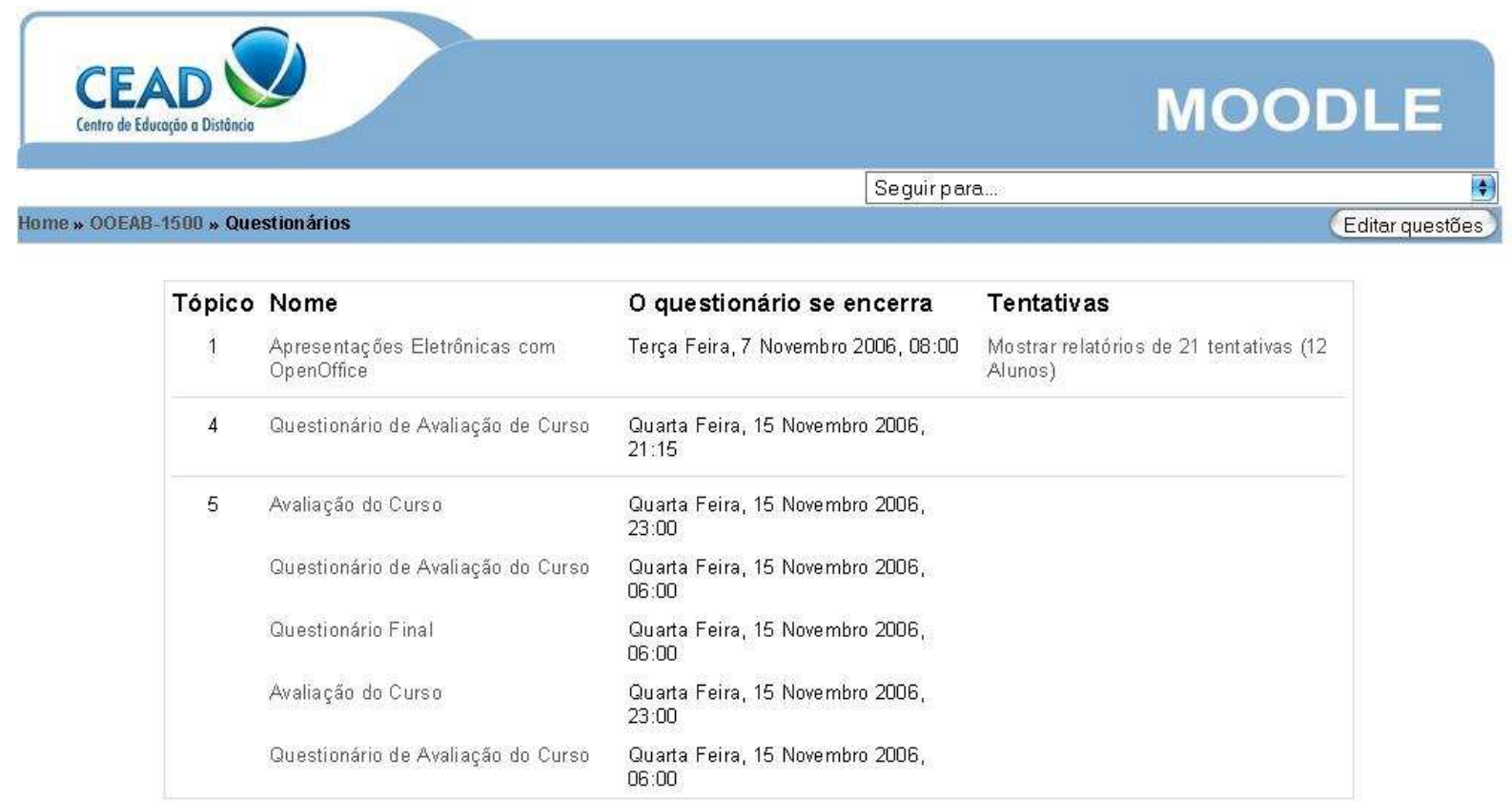

Figura 2.9: Questionario. 


\subsubsection{Wiki}

A Wiki é uma porção de páginas interligadas entre si e cada uma delas pode ser visitada e editada por qualquer pessoa. Uma característica notável das ferramentas Wiki é a facilidade de edição e a possibilidade de criação de textos de forma coletiva e livre.

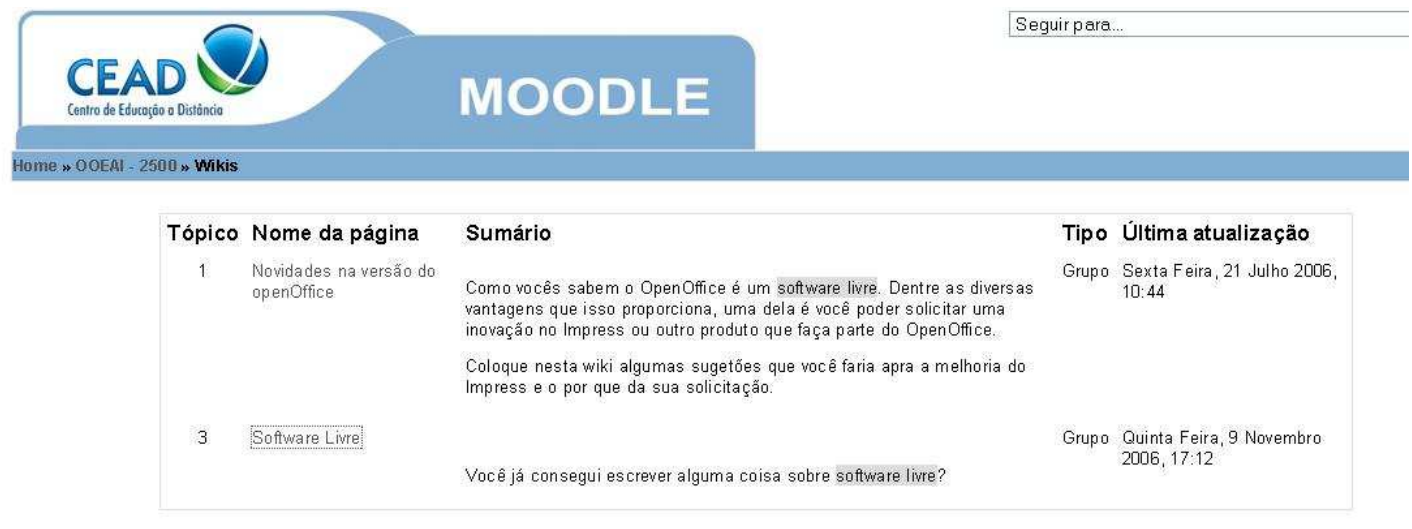

Você acessou como Rodrigo santos (Sair)

Figura 2.10: Wiki.

Depois de criar as atividades, fica fácil move-las para cima e para baixo na página de seu curso clicando nas pequenas setinhas para cima e para baixo próximas a cada atividade. e reeditar usando o ícone de edição. 


\subsubsection{Menu Administração}

A próxima figura mostra o Menu de Administração, o menu só pode ser visto desta forma se o acesso for feito pelo professor/tutor do curso. Este menu possui ferramentas específicas para uma fácil administração do curso.

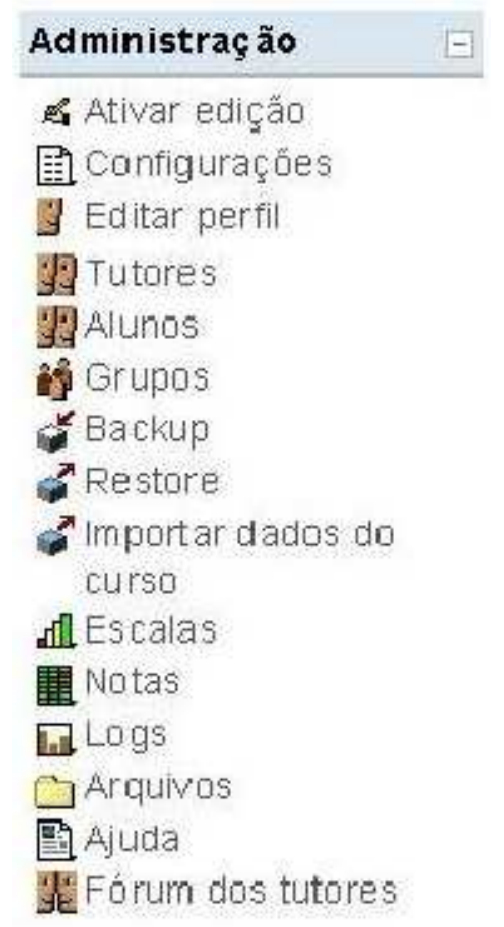

Figura 2.11: Menu de Administração.

\subsubsection{Filosofia do Moodle}

Origem: Moodledocs (MOODLE [2007])

O desenho e desenvolvimento do Moodle é guiado por uma filosofia de aprendizagem especial, um modo de pensar sobre o qual são encontradas referências, em poucas palavras, como uma pedagogia socioconstrucionista.Para se explicar o significado do termo "pedagogia socioconstrucionista", é preciso analisá-lo tendo por base quatro conceitos principais que estão por trás desse termo.

\subsubsection{Construtivismo no Moodle}

Este ponto de vista sustenta que as pessoas constroem novos conhecimentos activamente, na medida em que interagem com o seu ambiente. 
Tudo o que lê, vê, escuta, sente e toca é confrontado com seu conhecimento anterior e se estas experiências forem viáveis dentro de seu mundo mental, formarão um novo conhecimento que irá carregar consigo. O conhecimento é fortalecido se puder usá-lo sucessivamente no seu ambiente mais amplo. Você não é apenas um banco de memória absorvendo informação passivamente, nem o conhecimento lhe pode ser transmitido apenas por ler alguma coisa ou ouvir alguém.

Isso não significa que não consiga aprender nada da leitura de uma página na web ou assistindo a uma palestra. O que se quer realçar é que ocorre mais interpretação do que transferência de informação de um cérebro para outro.

\subsubsection{Construcionismo no Moodle}

O Construcionismo defende que a aprendizagem é particularmente efetiva quando constrói alguma coisa para outros experienciarem. Isso pode ser qualquer coisa desde uma frase falada ou uma mensagem na internet, até artefatos mais complexos como uma pintura, uma casa ou um pacote de software.

Por exemplo, pode ler esta página várias vezes e ainda assim esquecêla, mas se tiver de tentar explicar estas ideias com as suas próprias palavras a outros, ou produzir uma apresentação em slides explicando estes conceitos, então a investigação diz que terá uma compreensão melhor e mais integrada. Esse é o motivo porque as pessoas fazem anotações durante as aulas, mesmo que nunca leiam as anotações novamente.

\subsubsection{Construtivismo Social}

Este conceito estende as ideias acima para um grupo social construindo coisas umas para as outras, criando, de forma colaborativa, uma pequena cultura de objetos compartilhados, com significados compartilhados. Quando alguém é introduzido dentro de uma cultura como esta, está a aprender constantemente sobre como ser uma parte dessa cultura, a vários níveis.

Um exemplo bem simples é um objeto como um copo. O objeto pode ser usado para muitas coisas, mas o seu formato sugere algum conhecimento sobre conter líquidos. Um exemplo mais complexo é um curso on-line: a aparência das ferramentas do software não apenas indica determinados aspectos de funcionamento do curso, mas também as atividades e textos produzidos dentro do grupo como um todo, que ajudarão a moldar como cada pessoa se comporta dentro desse grupo. 


\subsubsection{Comportamento Conectado e Separado}

Esta ideia observa mais a fundo as motivações das pessoas numa discussão. Comportamento separado é quando alguém tenta permanecer objectivo e factual, e tende a defender suas próprias ideias usando a lógica para encontrar furos nas ideias dos seus oponentes. Comportamento conectado é uma abordagem mais empática que aceita a subjetividade, tentando ouvir e fazer perguntas num esforço para entender o ponto de vista do outro. Comportamento construído ocorre quando uma pessoa é sensível a ambas as abordagens e é capaz de escolher uma delas como apropriada à situação em que se encontra.

Em geral, uma quantidade saudável de comportamento conectado dentro de uma comunidade de aprendizagem é um estimulante poderoso para a aprendizagem, não apenas aproximando as pessoas mas promovendo reflexões mais profundas e re-exame das crenças existentes.

\subsubsection{Concluindo o Moodle}

Refletindo sobre estas abordagens ao ensino-aprendizagem, poderemos passar de um modelo passivo, de delivery, para um ensino mais centrado no aluno, baseado no que este faz, no seu papel enquanto problem-solver e indivíduo social que aprende com os outros. Pode também ajudá-lo a entender como cada participante de um curso pode ser tanto um professor como um aluno. Várias linhas de investigação têm apontado neste sentido (veja-se por exemplo o http://www.provost.harvard.edu/reports/UPCSE_Interim_Report.pdf realçando o papel do aluno na aprendizagem). Este pode ser um influenciador e modelo exemplar da cultura da classe, ligando-se aos alunos de um modo pessoal que detecta as suas necessidades de aprendizagem, e facilitando discussões e atividades de um modo que leve os alunos, coletivamente, em direção aos objetivos de aprendizagem da classe.

Obviamente o Moodle não força este estilo de comportamento, foi feito para o optimizar. No futuro, à medida que a infraestrutura técnica do Moodle se for tornando mais estável, promover avanços de cariz pedagógico será a principal direção de desenvolvimento. 


\section{Capítulo 3}

\section{A Pesquisa}

\subsection{Instrumento}

A metodologia de pesquisa utilizada foi o estudo baseado nas indicações de NISBETT e WATTS (NISBETT and WATT [1978]) (apud ANDRE [2005]), que caracterizam o desenvolvimento dos estudos de caso em três fases:

- Analise exploratória e qualitativa;

- Delimitação do Estudo para coleta de dados; e

- Analise dos dados.

\subsubsection{Analise Exploratória e Qualitativa}

"(...) é o momento de definir a(s) unidades(s) de análise (o caso), confirmar (ou não) as questões iniciais, estabelecer os contatos preliminares para entrada em campo, localizar os participantes e estabelecer mais precisamente os procedimentos e instrumentos de coleta de dados." (NISBETT and WATT [1978]) (apud ANDRE [2005])

Essa fase foi marcada pela busca de materiais que deram suporte a pesquisa onde todo o desenvolvimento da Revisão Teórica foi feito e pesquisado. As buscas em livros e na Internet foram constantes à procurar embasamento teórico a respeito de interatividade, construtivismo e Construcionismo.

Foram feitas algumas visitas ao CEAD em busca de dados estatísticos dos últimos semestres da disciplina IMI, esses dados serviram como parâmetro 
para se ter uma real idéia da evolução da disciplina quanto aos seus módulos virtuais, dessa forma pode ser averiguada a situação do projeto de tornar a disciplina totalmente on-line. Ainda na analise da disciplina IMI foram aproveitados dados e aulas dadas pela Prof ${ }^{a}$ Ms. Maria de Fátima Ramos Brandão, pela Prof ${ }^{a}$ Daniela Silva dos Anjos e pela Prof ${ }^{a}$ Jaqueline Moreira da Silva. Estes dado foram somados a experiência como aluno de Teoria e Prática Pedagógica em Informática 12 , TPPI 1 e TPPI 2, que são os estagiários e professores de IMI, respectivamente.

As experiências obtidas como professor determinaram o escopo do trabalho e da pesquisa, foi durante essa experiência que se pode verificar mais de perto a Plataforma Moodle. O contato com os alunos foi determinante na verificação de questões de interatividade, na necessidade de se oferecer interação de uma forma mais concreta e que realmente fizesse com que o aluno se sentisse mais próximo e integrado com a disciplina e com a turma de um modo geral.

\subsubsection{Delimitação do Estudo para Coleta de Dados}

"(... ) ùma vez identificados os elementos-chave e os contornos aproximados do estudo, procede-se à coleta sistemática de dados, mediante fontes variadas, instrumentos (mais ou menos) estruturados, em diferentes momentos e em situações diversificadas." (NISBETT and WATT [1978]) (apud ANDRE [2005])

Devido à quantidade de alunos que o CEAD atinge através da plataforma Moodle, a pesquisa foi restringida a apenas alguns alunos da disciplina Introdução a Micro Informática - IMI.

IMI foi escolhida pela diversidade de alunos que abrange devido ser uma matéria obrigatória para diversos cursos da UNB. Outra razão ara a escolha da disciplina para a base de dados é que os professores de IMI são alunos de TPPI 2 que, em sua grande maioria, estão no final do curso de Computação na UNB, logo a sua experiência durante todo o curso faz com que os professores tenham uma grande inclinação para o uso de tecnologias nas aulas.

O instrumento escolhido para fazer a coleta destes dados foi um questionário elaborado conforme as experiências obtidas como professor de IMI tendo em vista que verificassem:

1. - A interatividade nas turmas;

2. - a contrução do conhecimento através das ferramentas do ambiente.

3. - o papel do professor ao propiciar situações e exercícios para trabalhar questões de interatividade, construtivismo e construcinismo. 


\subsubsection{Analise Sistemática dos Dados}

"(...) mediante procedimentos analíticos, procura -se verificar a pertinência das questões selecionadas frente às características específicas da situação estudada e são tomadas decisões sobre áreas a serem mais exploradas, aspectos que merecem mais atenção e outros que podem ser descartados." (NISBETT and WATT [1978]) (apud ANDRE [2005])

\subsubsection{Dados da Pesquisa}

1 - Qual a sua idade?

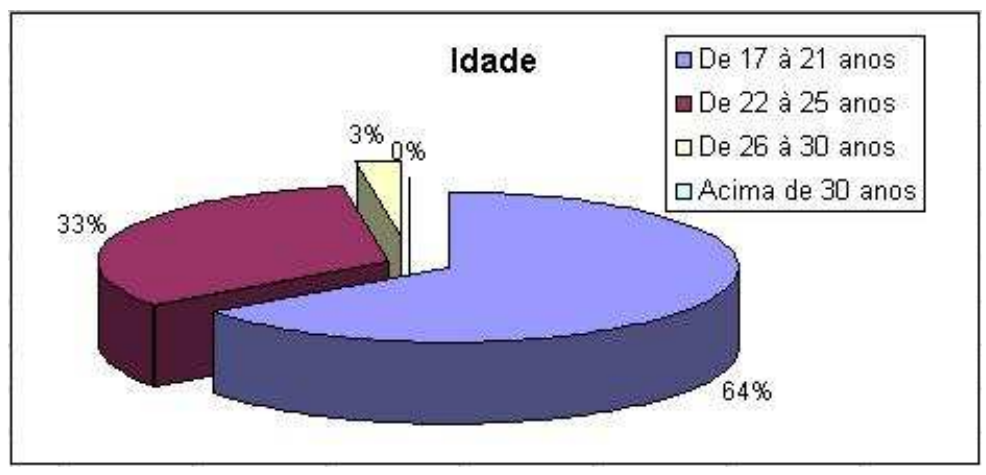

Figura 3.1: Gráfico Idade.

2 - Você já fez outras disciplinas total ou parcialmente on-line? Se sim, quantas?

\begin{tabular}{|c|c|c|}
\hline \multicolumn{3}{|c|}{2 - Quantidade de disciplina com o auxilio do Moodle } \\
\hline & quantidade & porcentagem \\
\hline não & 15 & $38,46 \%$ \\
\hline 1 & 12 & $30,77 \%$ \\
\hline 2 & 7 & $17,95 \%$ \\
\hline 3 & 3 & $7,69 \%$ \\
\hline 4 & 2 & $5,13 \%$ \\
\hline mais de 4 & 0 & $0,00 \%$ \\
\hline Total & 39 & \\
\hline
\end{tabular}

Tabela 3.1: Tabela Quantidade de Disciplinas feitas no Moodle 
3 - Em média quantas vezes por semana você acessa o ambiente Moodle da disciplina IMI?

\begin{tabular}{l}
\hline 3 - Em média quantas vezes por semana você \\
acessa o ambiente Moodle da disciplina IMI? \\
\begin{tabular}{|c||c|c|}
\hline & quantidade & porcentagem \\
\hline 0 & 1 & $2,50 \%$ \\
\hline 1 & 8 & $20,00 \%$ \\
\hline 2 & 19 & $47,50 \%$ \\
\hline 3 & 5 & $12,50 \%$ \\
\hline 4 & 3 & $7,50 \%$ \\
\hline 5 ou mais & 4 & $10,00 \%$ \\
\hline Total & 40 & \\
\hline
\end{tabular}
\end{tabular}

Tabela 3.2: Tabela Acesso Semanal

4 - Seus acessos ao ambiente da disciplina ficaram mais freqüentes no decorrer do semestre?

\begin{tabular}{l}
\hline \multicolumn{3}{|c||}{ - Aumento dos acessos durante o semestre } \\
\begin{tabular}{|c|c|c|}
\hline & quantidade & porcentagem \\
\hline Sim & 35 & $87,50 \%$ \\
\hline não & 5 & $12,50 \%$ \\
\hline
\end{tabular}
\end{tabular}

Tabela 3.3: Tabela Aumento do Acesso Durante o Semestre

5 - Os alunos puderam participar do processo de construção do curso dando opiniões nos fóruns ou nas listas de Discussões?

\begin{tabular}{l}
\hline \multicolumn{3}{c|}{5 - Participação na Construção da Disciplina } \\
\begin{tabular}{|c||c|c|}
\hline & quantidade & porcentagem \\
\hline Sim & 26 & $70,27 \%$ \\
\hline não & 11 & $29,73 \%$ \\
\hline Total & 37 & \\
\hline
\end{tabular}
\end{tabular}

Tabela 3.4: Tabela Participaço na Construção da Disciplina 
6 Algumas das opiniões dadas pelos alunos foram aproveitadas? Dê exemplo de alguma.

* A maioria dos alunos disseram sim, segue os exemplos dados pelos alunos:

- Tópicos e tarefas mudados e melhorados através de opiniões dos alunos;

- Datas das Provas; e

- Ordem do Curso.

7 - Você emitiu opiniões nas listas de discussão?

\begin{tabular}{l}
\hline $\begin{array}{l}\text { 7 - Você emitiu opiniões nas listas } \\
\text { de discussão? }\end{array}$ \\
\begin{tabular}{|c||c|c|}
\hline & quantidade & porcentagem \\
\hline sim & 5 & $14,29 \%$ \\
\hline não & 30 & $85,71 \%$ \\
\hline Total & 35 & \\
\hline
\end{tabular}
\end{tabular}

Tabela 3.5: Opiniões em Listas

8 - Qual a nota que você daria à participação dos seus colegas nos fóruns, no wiki e no chat?

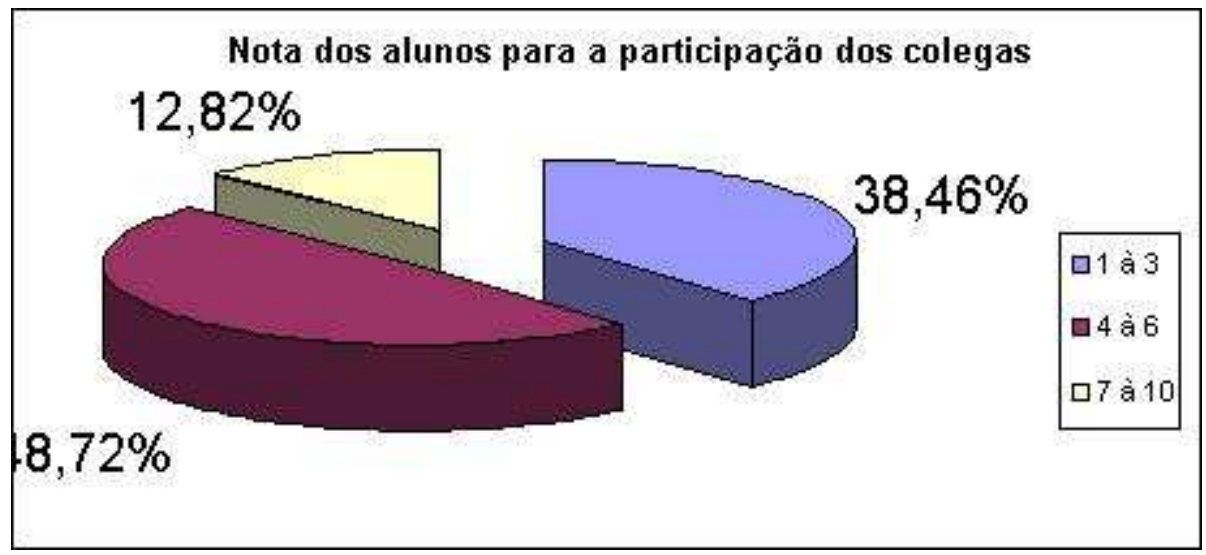

Figura 3.2: Participação dos Colegas 
9 - Qual avaliação que você faz dessas ferramentas comunicativas?

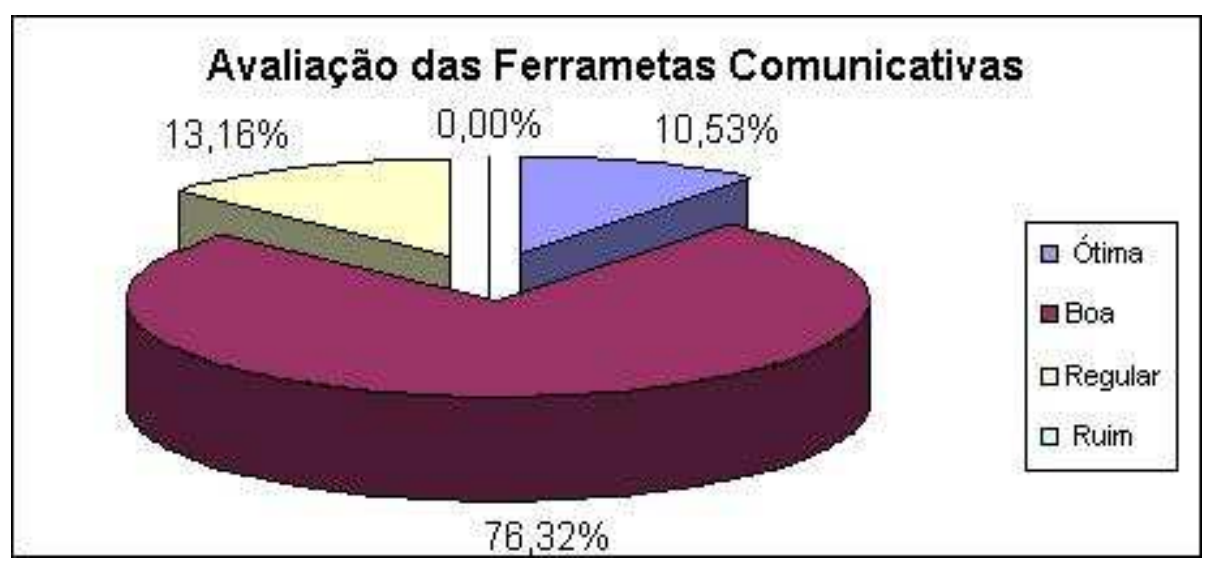

Figura 3.3: Avaliação das Ferramentas Comunicativas.

10 - Com as experiências obtidas durante o semestre no Moodle, qual Ferramenta Comunicativa você mais gostou?

\begin{tabular}{|c|c|c|}
\hline \multicolumn{3}{|c|}{$\begin{array}{c}10 \text { - Com as experiências obtidas durante o semestre no Moodle, } \\
\text { qual Ferramenta Comunicativa você mais gostou? }\end{array}$} \\
\hline & quantidade & porcentagem \\
\hline Homepage & 13 & $37,14 \%$ \\
\hline Enquetes & 15 & $42,86 \%$ \\
\hline Fórum & 5 & $14,29 \%$ \\
\hline Wiki & 1 & $2,86 \%$ \\
\hline Chat & 1 & $2,86 \%$ \\
\hline Total & 35 & \\
\hline
\end{tabular}

Tabela 3.6: Ferramenta Que Mais Gostou

11 - Enumere de 1 à 5 as ferramentas abaixo que você mais usou, sendo 1 a ferramenta mais usada.

11 - Enumere de 1 à 5 as ferramentas abaixo que você mais usou, sendo 1 a ferramenta mais usada.

\begin{tabular}{|c||c|c|}
\hline & quantidade & porcentagem \\
\hline Materiais & 75 & $33,94 \%$ \\
\hline Fórum & 50 & $22,62 \%$ \\
\hline Wiki & 25 & $11,31 \%$ \\
\hline Chat & 24 & $10,86 \%$ \\
\hline Links & 47 & $21,27 \%$ \\
\hline Total & 221 & \\
\hline
\end{tabular}

Tabela 3.7: Escala das Ferramentas mais Usadas 
12 - Enumere de 1 a 5 as ferramentas abaixo que mais contribuíram para sua aprendizagem sendo 1 a ferramenta que mais contribuiu.

12 - Enumere de 1 a 5 as ferramentas abaixo que mais contribuíram para sua aprendizagem sendo 1 a ferramenta que mais contribuiu.

\begin{tabular}{|c||c|c|}
\hline & quantidade & porcentagem \\
\hline Materiais & 77 & $34,84 \%$ \\
\hline Fórum & 44 & $19,91 \%$ \\
\hline Wiki & 29 & $13,12 \%$ \\
\hline Chat & 23 & $10,41 \%$ \\
\hline Links & 48 & $21,72 \%$ \\
\hline Total & 221 & \\
\hline
\end{tabular}

Tabela 3.8: Escala das Ferramentas que Mais Contribuiram Para o Prendizado

13 - Como você classificaria o incentivo dos professores à participação dos alunos no Moodle?

$$
13 \text { - Como você classificaria o incentivo dos professores }
$$

à participação dos alunos no Moodle?

\begin{tabular}{|c||c|c|}
\hline & quantidade & porcentagem \\
\hline Ótimo & 10 & $26,32 \%$ \\
\hline Bom & 23 & $60,53 \%$ \\
\hline Regular & 4 & $10,53 \%$ \\
\hline Ruim & 1 & $2,63 \%$ \\
\hline Total & 38 & \\
\hline
\end{tabular}

Tabela 3.9: Incentivo do Professor

14 - Você teria melhorias a sugerir para o aperfeiçoamento da metodologia da disciplina? Quais?

* A maioria das sugestões dos alunos foram:

- Mais atenção com os que têm mais dificuldades

- Melhores Equipamentos

- Menos assunto para praticar mais cada conteúdo

- Mais aulas

- Melhores monitores de turma 
15 - Você acredita que na metodologia da disciplina houve um diálogo entre professor e aluno? Justifique e exemplifique?

* Os alunos responderam que o diálogo que houve entre professor e aluno ficaram no campo dos questionamentos quanto a algumas questões, que os professores estiveram presentes nos fóruns e sempre tirando dúvidas e respondendo as questões.

16 - Sendo a disciplina IMI presencial e on-line, qual das modalidades mais contribuiu na construção da sua aprendizagem? Por quê?

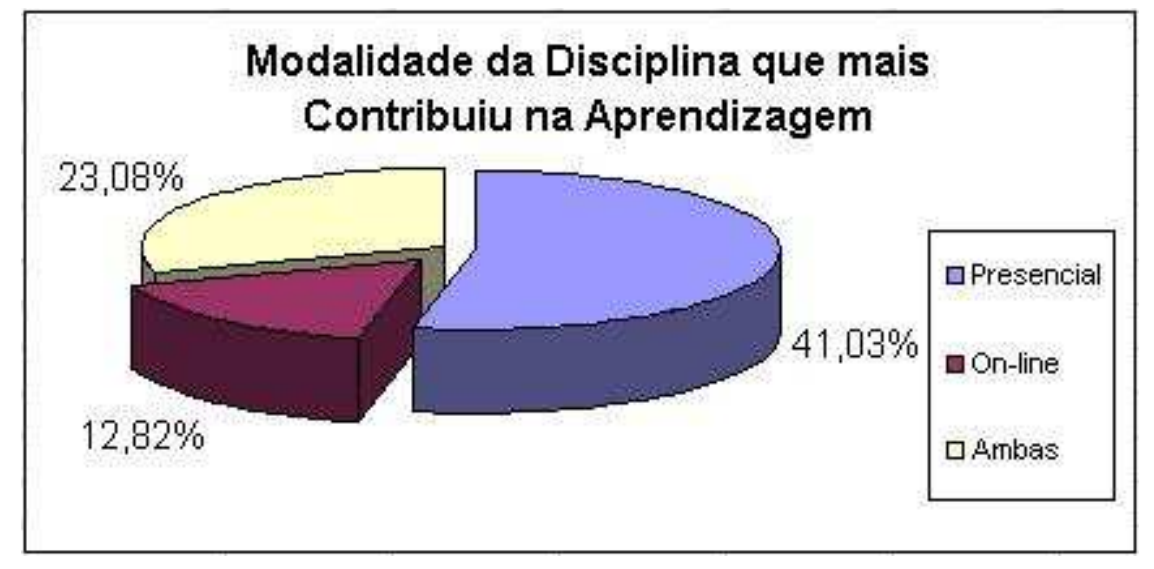

Figura 3.4: Gráfico Modalidade Preferida

* Dos alunos que escolheram o modo Presencial as justificativas para essa escolha estão em:

- Tirar dúvidas

- Melhor exposição do conteúdo

- Melhor compreensão do conteúdo

* Dos que escolheram o modo On-line as justificativas foram:

- Mais prática

- Facilidade do Tempo

- Conteúdo mais completo

- Locomoção

* Dos que escolheram os 2 modos, tanto o Presencial quanto o On-line, justificaram suas escolhas com:

- Conteúdo no modo Presencial e Boa prática no modo On-line 
17 - Faça uma auto avaliação crítica da sua participação na disciplina no que diz respeito a aprendizagem, participação e desenvolvimento de trabalhos coletivos.

* A maioria diz que a participação foi boa e que aprendeu a matéria, uma pequena parte disse que não participou, mas que aprendeu a matéria. Um aluno relatou que o que aprendeu não é útil para usar onde ele trabalha.

\subsubsection{Discussão}

O Moodle é muito mais do que muitos imaginam, poucos professores usam essa plataforma com toda sua capacidade, ou ainda, são poucos que aproveitam suas facilidades e funcionalidades. Ao usar o Moodle apenas como repositório de arquivos, uma espécie de HD virtual, os professores deixam de aproveitar essa poderosa ferramenta tecnológica, que seria muito bem empregada para diversificar a metodologia de ensino, deixam de renovar a sua didática restringindo, assim, seus alunos quanto à introdução a essa nova área do ensino, onde a relação tempo e espaço é otimizada, propiciando um melhor aproveitamento de ambos no cotidiano dos indivíduos envolvidos.

Para uma ferramenta ser bem aproveitada e bem utilizada é preciso conhecê-la bem, e sendo o Moodle uma ferramenta riquíssima para os ambientes virtuais de EAD, para que se possa usá-la com todo seu potencial é preciso que o professor não só entenda o como usar a ferramenta, suas aplicações e possibilidades de uso, é necessário que ele também saiba o "para que" ele foi criado, e para isso é importante conhecer duas de suas bases filosóficas: o construtivismo e o construcionismo.

Ambas as bases fazem referências a uma forma de aprendizagem onde o indivíduo constrói o próprio conhecimento, seja no construtivismo onde o individuo aprende através de uma interação com o objeto observado, seja no construcionismo onde o indivíduo aprende criando para o outro aprender. Para que o Moodle seja bem utilizado e atinja seus objetivos é preciso que o professor crie um curso na plataforma onde essas bases filosóficas sejam bem trabalhadas e para isso é preciso que o ambiente virtual propicie uma interação com o aluno que seja forte o suficiente a ponto de leva-lo a essas construções do saber.

A interação é a grande chave para o sucesso do Moodle, e ela não pode ficar apenas no campo dos cliques do mouse escolhendo opções nas telas dos navegadores, tem que ir muito além, o indivíduo tem que interagir com o ambiente a tal ponto que se sinta parte de um grupo mesmo que não o veja, tem que se identificar com o grupo mesmo que não conheça ninguém pessoalmente, e para isso a interatividade tem que ser mais que um simples convite a participar, 
tem que ser induzida para que, na medida em que o tempo passe, o aluno se sinta mais parte da turma da qual ele está inserido no ambiente.

A pesquisa feita com alguns alunos de IMI serve como um modelo para diagnosticar problemas e para que se faça uma análise do uso do Moodle hoje pela disciplina, para que se possa rever alguns pontos, favorecendo os pontos fortes e melhorando o que tiver que ser melhorado.

Ao se analisar os dados da pesquisa, nota-se, segundo o item 3 do questionário, que $47 \%$ dos alunos entrevistados acessam o ambiente apenas duas vezes pro semana, isso revela um grave problema, pois se o aluno acessa poucas vezes o ambiente quer dizer que ele não está interagindo como deveria, levando assim, a uma quebra de continuidade no curso, pois o lapso de tempo entre os acessos fica gigantesco, impedindo assim que o aluno crie uma identificação com o ambiente, e não só com o ambiente mas com todos os alunos e com o próprio professor que está por traz da disciplina.

Se, segundo a sociologia, uma pessoa para ter um bom nível de segurança precisa interagir e se sentir pertencente a um grupo ou uma comunidade, para realmente torna-lo um membro participativo tem que se criar níveis de interação que o levem a essa segurança fazendo-o se se sentir inserido no grupo, e quando isso não acontece faz com que as pessoas não se sintam parte do grupo e logo não construam o próprio conhecimento pois não irão interagir com o objeto pesquisado e nem criarão para outros aprenderem.

As disciplinas ou cursos que forem disponibilizados no ambiente virtual têm que ter como um dos objetivos principais, seja em suas atividades ou no uso de qualquer ferramenta comunicativa, fomentar a interação do indivíduo na plataforma, pois a interação é o que vai levar o indivíduo a se sentir seguro no ambiente o que o leva a construir seu conhecimento.

As questões 10, 11 e 12 do questionário indicam as ferramentas comunicativas que os alunos mais gostaram, a que eles mais usaram e a que mais contribuiu para o aprendizado respectivamente. Estas questões mostram que apesar do Fórum, com 42,86\% da preferência, ser a ferramenta que os alunos mais gostam, não quer que dizer foi a que mais usaram e nem a que mais contribuiu para o aprendizado. Nas questões 11 e 12, foi pedido que os alunos atribuísse a cada ferramenta comunicativa um número na escala de 1 a 5 , onde seria atribuído 5 pontos para a ferramenta que eles mais usaram e que mais houvesse contribuído para o aprendizado, e 1 ponto para a que menos usaram e a que menos tivesse contribuído na aprendizagem. Dessa forma essas questões mostraram que quanto ao uso os materiais ficaram em primeiro com 75 pontos, os fóruns em segundo com 50 pontos e em seguida os links com 47 pontos e quanto á que mais contribuiu os Materiais ficaram com 77 pontos, os links em segundo com 48 pontos e os fóruns em terceiro com 44 pontos. 
Independente da ordem do fórum e dos links nas questões 11 e 12 estarem alternadas, o fato de gostarem do fórum indica uma forte tendência à participação, pois os fóruns servem para dar avisos, idéias, sugestões e para que os alunos tirem as dúvidas, e essa ferramenta requer um nível de interação e de participação que poderia ser aproveita para levar o aluno a construir seu conhecimento usando os materiais disponíveis, mas o fato dos alunos usarem mais os materiais e os links indica que talvez as ferramentas estejam sendo oferecidas de uma forma a não propiciar a interação e por mais que o item 5 do questionário mostre que $87 \%$ dos alunos aumentaram a quantidade de acessos durante o semestre indicando que houve algo na disciplina que fez com que os alunos entrassem mais no ambiente, algo este que tem que ser detalhado e focado, isso não favoreceu a interação como um todo, pois os materiais e os links não requerem um bom nível de interação.

Os links como ferramenta são riquíssimos quanto à variedade de materiais diferentes e como uma boa base bibliográfica. A leitura e estudo dos materiais oferecidos tanto para download na homepage do curso, quanto os oferecidos através de links, fazem que o aluno construa seu conhecimento em uma relação com o assunto, objeto de estudo, mas que sozinhos não favorecem a interação do aluno no ambiente. Se o aluno apenas estudar os materiais e não interagir no ambiente o aluno pode começar a ficar desmotivado quanto ao curso devido à quebra do principio da sociologia quanto ao nível de segurança principio descrito na seção 2.3. Os links e os materiais são ferramentas importantíssimas para o sucesso do ambiente, mas se estiverem sozinhos podem gerar resultados inesperados como o desinteresse do aluno e por conseqüência sua desistência do curso.

Ferramentas como a Wiki e os Chats, que são armas poderosas quanto à construção do conhecimento e que geram um nível de interação que diminuiria muito o problema da impessoalidade que a internet traz (FUKS and ASSIS [2001])(apud GEROSA and PEREIRA [2001]), ficaram em últimos lugares na preferência dos alunos entrevistados, revelando que a disciplina, por mais que use o Moodle, ainda não atingiu a maturidade que necessita, tanto referente à participação do aluno quanto para a construção do conhecimento dos mesmos.

Uma das definições de construtivismo diz que o indivíduo constrói o próprio conhecimento através de suas relações com o objeto (MORETTO [2003]), o aluno ao ter contato com o ambiente a sua relação com ele vai gerando o seu aprendizado conforme suas experiências. Quando o professor permite que o aluno ajude a construir o ambiente e a disciplina, ele favorece o nascimento de uma relação do aluno com a disciplina, ou ainda do aluno com o ambiente. O item 6 do questionário mostra que 70\% dos alunos enxergaram uma abertura, da parte dos professores, quanto a sua participação na criação disciplina através de dicas e opiniões nos fóruns e nas listas, mas essa abertura dos professores não foi suficiente para que eles participassem, pois, por mais livres que se sentissem o item 7 do questionário mostra que $85 \%$ dos alunos não deram opiniões nas listas de discussões, o que revela que os alunos se sentiram livres para participar mas 
que essa liberdade não foi suficiente para fazer com que eles participassem.

A disciplina IMI é um bom exemplo quanto á modalidade online, nela é oferecida um nível de interação, que quando comparado a outras disciplinas, indica seu potencial e a torna um referencial para cursos e para outras disciplinas. Mas mesmo IMI sendo um referencial como disciplina on-line, nota-se que os professores de IMI não estão aproveitando todo o potencial que as ferramentas do Moodle oferecem.

Ao oferecer uma interação ao aluno através do ambiente virtual, essa oferta tem que ser feita de uma forma a convidar o aluno a participar inserindoo não só no ambiente, mas também propiciando ao aluno um primeiro contato que gere uma boa primeira referência com o ambiente e com a disciplina. Esse primeiro convite tem que suprir as carências sociais do aluno e não precisa, necessariamente, estar atrelada a assuntos na área da disciplina.

Uma solução para que esse primeiro contato seja uma referência boa seria tornar a primeira aula presencial. Fazendo esse primeiro contato presencial o aluno poderia começar uma identificação com a turma e com o professor, nesse primeiro contato poderia ser ministrada, além das apresentações normais dos alunos, tutores e professores, uma breve aula de como usar o ambiente o que significa cada ícone na página do ambiente, uma amostra das ferramentas comunicativas e as opções de administração que os alunos têm no curso em questão.

Se hoje já existe uma consciência que o aluno precisa interagir para se sentir integrado em um grupo (VIEIRA [2002]), após esse primeiro contato presencial, cada espaço do ambiente tem que ser oferecido de forma a continuar a interação. O grande objetivo de uma disciplina ou curso on-line é que o aluno aprenda, pois foi para isso que se matriculou ou se inscreveu, mas o universo da disciplina pode ser estendido, de forma a oferecer um pouco mais do que apenas o conteúdo e ferramentas interligadas a este conteúdo, seria interessante oferecer espaços onde os alunos pudessem debater assuntos do cotidiano e de interesses diversos. Este espaço poderia ser um tipo de fórum geral onde os alunos pudessem colocar assuntos livres do conteúdo da disciplina, desde como realizar updates de computadores até postagem de poemas e textos diversos, desta forma o aluno a cada mensagem a cada debate iria se familiarizando mais com o grupo e isso aos poucos vai gerando uma identidade entre os componentes, fazendo com que os alunos se sintam inseridos levando-os a interagir entre si.

Conforme colocado na subseção 3.1.3.2 onde se discutiu os dados relativos ao questionário, as questões 10, 11 e 12 mostram que os chats e as wikis não são a preferência dos alunos, nem os mais usados e nem estão entre os que mais contribuíram para o aprendizado dos alunos. Segundo o item 15 do questionário, a maioria dos alunos, 41,03\%, ainda preferem as disciplinas presenciais 
e 23,08\% gostam de uma disciplina mista, parte on-line e parte presencial. A grande justificativa para estas escolhas está no fato em que os alunos ainda têm insegurança sobre como tirar as duvidas sendo a disciplina on-line, o medo de ter o material, mas de não ter como tirar as dúvidas, levam os alunos a escolher a modalidade presencial, e uma boa ferramenta para quebrar essa questão seria os Chats.

O chat oferece um tipo interação instantânea, essa ferramenta não seria trabalhada apenas como uma forma de interação social onde todos conversam sobre assuntos variados, muitos alunos poderiam tirar as dúvidas uns dos outros, e mesmo que alguns desses alunos não tenham dúvidas, eles aprenderiam na relação com as dúvidas colocadas nos chats. Desta forma os alunos estariam trabalhando tanto o construtivismo como o construcionismo levando ao sucesso do ambiente virtual quanto a construção do conhecimento do aluno e quanto ao crescimento do nível de segurança do aluno (VIEIRA [2002]), pois se o aluno aprender com a dúvida de outro aluno ele estará construindo o próprio conhecimento através da relação com o objeto estudado que, neste caso, são as dúvidas dos outros alunos, e quando ele tira a dúvida de alguém ele está construindo para que outro aluno aprenda.

Como visto também na subseção 3.1.3.2, alguns dados dos itens 6 e 7 do questionário, mostram que por mais que os alunos tenham se sentido livres para participar essa abertura á participação não gerou a interação necessária para que os alunos participassem. Da mesma forma não é apenas oferecendo um espaço no ambiente para os chats que os alunos irão participar. O professor tem que oferecer algo que fomente nos alunos o desejo ou uma quase obrigação de participar do chat. Ele pode fazer isso de várias formas:

1. - Ele sempre estando on-lina nas horas marcadas para tirar dúvidas;

2. - Dando nota para participação nos chats; ou

3. - Oferecendo a oportunidade de ganhar nota sendo uma espécie de Xerife no ambiente, a cada dia ou semana, um aluno é responsável por estar no chat durante um perido do dia.

Outras formas podem ser criadas, vai depender da criatividade do professor e do tipo de turma que o professoer tem nas mãos, o importante é que essa interação através dos chats seja algo comum e contínuo para que o aluno se acostume e se sinta livre no ambiente on-line.

Os itens 11 e 12 do questionário mostraram que as ferramentas que os usuários mais usaram e que mais contribuiu na construção do conhecimento foram os materiais. A wiki, é uma ótima forma de construção de conhecimento, ela pode ser usada na construção de um material feito pela própria turma. $\mathrm{Na}$ medida em que o semestre passa, o professor pode oferecer assuntos, referentes à 
disciplina, para que os alunos definam, conforme seus conhecimentos ou através de buscas on-lines, e vão formando as wikis.

O construcionismo traz justamente que o ser humano constrói seu conhecimento quando cria para outro ser humano (ELKAIM [1998]). Quando os alunos começarem a definir os temas, estudados ou não, na Wiki, ele vai aprendendo com o que vai colocando no ambiente, e serve como um guia para estudo e, na medida em que o semestre vai passando, as definições vão ficando mais completas. O professor, ao oferecer essas ferramentas comunicativas, tem que ficar sempre atento para corrigir o que estiver errado ou definido de forma errada, para que não haja nada que leve os alunos a compreenderem um determinado tema de erroneamente.

Uma questão muito importante em ambientes viertuais está ligada à atitude do professor no ambiente. O professor que não participa do ambiente, ou não investe tempo em preparar o ambiente para os alunos, deixa os alunos inseguros, o que leva a uma diminuição do nível de segurança do aluno (VIEIRA [2002]), pois se ele já não vê o professor e ainda sente que o professor não está presente ou que o professor não está dando suporte a ele no ambiente, isso pode leva-lo a achar que não existe ninguém ali por traz da disciplina.

Essa insegurança impede que o aluno interaja como deveria assim o aluno não participa, não constrói o próprio conhecimento, pois não vai haver um relacionamento como deveria haver com o objeto de estudo, e nem constrói para que o outro aprenda, quebrando a fórmula de aprendizagem que o Moodle oferece.

Para o Professor impedir essa insegurança tem que estar sempre presente no ambiente, mandando e-mails e mensagens, participando sempre dos chats e dos fóruns, enviando temas variados nos fóruns, verificando a participação do aluno no ambiente, e se por um acaso detectar que algum aluno participa pouco ou que ele tenha entrado pouco no ambiente durante a semana, procurar entrar em contato com o aluno mandando mensagem, e-mail, perguntando nos fóruns e até ligando para que o aluno saiba que faz parte de um grupo. É preciso que o professor evite também demorar a dar respostas nos fóruns e nas mensagens de e-mail, para que fique evidente seu o interesse e que mostre ara o aluno que ele está presente.

Tudo isso dá ao aluno uma paz quanto ao suporte da disciplina, pois ele sabe que pode contar com o professor e que ele, o professor, estará disponível quando o aluno precisar. 


\section{Capítulo 4}

\section{Conclusões e Trabalhos Futuros}

A idéia é sempre melhorar, analisar o crescimento, analisar o andamento, olhar para traz para ver erros, analisar as dificuldades para que o próximo modelo seja melhor que o último. Esse trabalho se propôs a isso, olhar para o que se tem hoje como ambiente, através da disciplina de IMI, para se oferecer um modelo melhor que o último.

O fato de a pesquisa não ter sido feita com todos os alunos do CEAD que têm aula em ambientes virtuais, não quer dizer que a mesma seja falsa, apenas não pode ser conclusiva. A escolha da pesquisa na disciplina de IMI não foi por acaso, foi escolhida porque IMI é oferecido por um instituto onde a tecnologia e inovação é algo comum, o instituto de Ciências da Computação. Tendo-se assim um ótimo modelo para se analisar.

A análise feita apenas indica que existe um bom trabalho e um esforço na disciplina de IMI em se oferecer o melhor, mas que mesmo assim o que se tem oferecido não é o melhor possível, é claro que, como em tudo que é recente, existem coisas a se melhorar, e parar agora para fazer o feedback é importante para que uma boa base seja estruturada.

Em IMI pode se ver isso, a cada semestre o semestre anterior é revisto, analisado e melhorado, isso leva a um crescimento e desenvolvimento da disciplina mas não um crescimento desordenado, mas sim um crescimento sustentando pelo melhoramento das técnicas através dessas revosões.

Futuros trabalhos poderão avaliar se as questões e soluções levantadas neste estudo de caso averiguando se contribuíram ou não para a melhoria da disciplina quanto a interação, ao construtivismo e ao construcionismo.

Poderá ser feito também uma ampliação da pesquisa, analisando também outros grupos e outras disciplinas, para que o banco de dados possa ser mais completo e a pesquisa mais conclusiva. 


\section{Bibliografia}

ALVES, J. A. M. (1994). A educaç ao a distância no brasil: Sintese historica e perspectiva.

ANDRE, M. E. D. (2005). Estudo de caso em pesquisa e avaliaç ao educacional.

ARETIO, L. G. (1994). Educación a distancia hoy.

DEMO, P. (1995). Sociologia: Uma introdução crítica.

DEMO, P. (sem data).

DOHMEN, G. (1967). Distance education international perspectivs.

DORNELLES, R. J. (2001). A utilização de tecnologias de internet na educaço a distância.

ELKAIM, M. (1998). Panorama das terapias familiares.

FUKS, H. and ASSIS, R. L. (2001). Facilitating perception on virtual learningware - based environments.

GERGEN, K. (1985). The social constructionist movement in modern psychology.

GerosA, M. A. and PEREIRA, C. J. (2001). Elementos de percepção como forma de facilitar a colaboração. laboratorio de engenharia de software, page 2.

GRANDESSO, M. A. (2001). Reconstruindo significados na pratica clinica.texto extraido da mesa redonda no xiii ifta. world family therapy congress.

HAREL (1991). Children designers.

HOLMBERG, B. (1981). Educacion a distancia situaciaon y perspectivas.

LANDIN, C. M. (1997). Educação a distância: algumas considerações.

MARTINS, O. B. (1991). A educaç ao superior à distância e a democratiaç ao do saber.

MASON, R. and KAYE, A. (1989). Mindwave communication, computers and distance education. URLhttp://wwwicdl.open.ac.uk/mindweave/mindweave.html . 
MOODLE (acessado em 2007). Guia de funcionalidades do moodle.

MOORE, M. G. (1972). Learner autonomy the second dimension of independent learning convergence.

MOORE, M. G. and KEARSLEY, G. (1996). Distance education: a system view.

MORETTO, V. P. (2003). Construtivismo: a produção do conhecimento em aula.

NISBETT, J. and WATT, J. (1978). Case study red guide 26. guides in education research.

NUNES, I. B. (1992). Noç oes de educaç ao a distância. URL¡http: www.ibase.org.br/ ined/ivoniol.htmli.

PAPERT, S. (1994). A maquina das crianças: repensando a escola na era da informatica.

PIAGET, J. (1975). A formação do simbolo na criança.

PRADO, M. E. B. B. (sem data). O uso do computador na formação doprofessor: um enfoque reflexivo da pratica pedagogica.

PRETI, O. (1996). Educação a distância: uma pratica educativa mediadora e mediatizada.

RANGEL, A. P. F. (2004). Introdução ao moodle. ambiente de aprendizagem modulo 1.

UNIVERSITY, O. (acessado em 2007). Open University. Inglaterra.

VALENTE, J. A. (1999). O computador na sociedade do conhecimento.

VIEIRA, R. P. (2002). Interação:anlise em programas de educação a distância.

WEISS, A. M. L. and da CRUZ, M. L. (1999). A informatica e os problemas escolares de aprendizagem. 